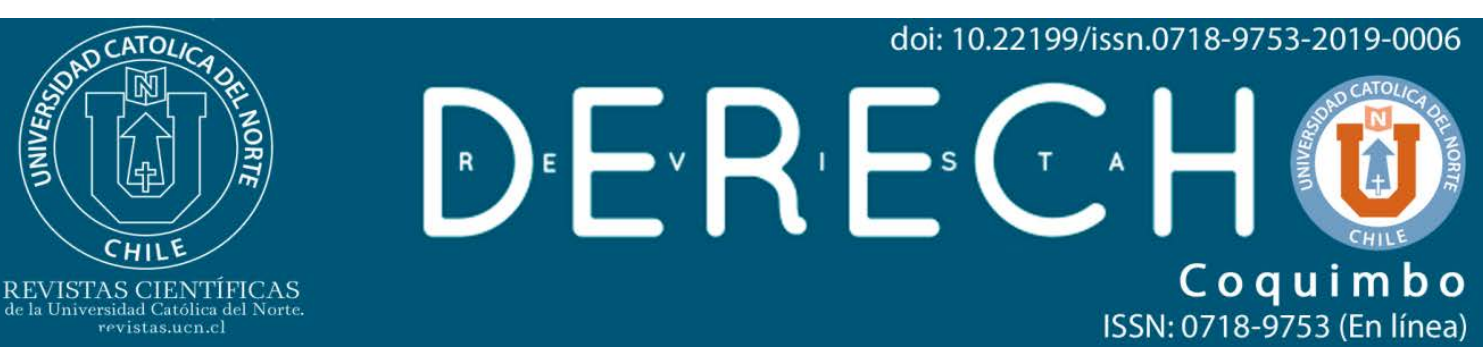

\title{
Corrupción entre particulares: lesividad de la conducta y consecuencias en sede de tipificación de acuerdo al análisis comparado
}

\author{
Private-to-private corruption: harmfulness of the conduct and con- \\ sequences of its criminalization according to a comparative criminal \\ law analysis \\ Osvaldo Artaza Varela * (1) https://orcid.org/0000-0001-8453-5069 \\ *Universidad de Talca, Chile. Profesor. Doctor en Derecho y Cs. Políticas, U. de Barcelona

\section{Resumen:}

Se pretende abordar el fenómeno de la criminalización de la corrupción entre particulares, proponiendo tener en cuenta una serie de distinciones, que se extraen del análisis del ámbito comparado, relativas a los fundamentos de la criminalización, esto es, al problema de los bienes jurídicos que se podrían proteger a través de esta figura y a la constatación de una serie de problemas interpretativos que podrían presentar como producto de la fórmula escogida por el legislador para su tipificación. En este sentido se pretende dar cuenta de una serie de dificultades, asociadas a su criminalización, relacionadas con la posibilidad de generación de malos entendidos que podrían disminuir la aplicación correcta del precepto de cara a los intereses que se pretenden proteger.

Palabras Clave: Corrupción en los negocios; Soborno; Competencia leal; Difuminación entre el sector público y privado.

\begin{abstract}
:
The phenomenon of criminalization of corruption in the private sector by considering a series of distinctions, detected in a comparative criminal law analysis, regarding the justification of its criminalization: the problem of the legal interests that may be protected through this crime. But also, by identifying a series of interpretative problems that may present as an outcome of the specific criminalization formula adopted by the legislator. In this sense, it is pretended to account for a series of difficulties associated to its criminalization, related to the possibility of emergence of some misunderstandings that may diminish the correct application of the crime, especially considering the legal interests that it pretends to protect. Keywords: Business corruption; Bribery; Fair competition; Erosion (blurring) of the private and public sector division.
\end{abstract}




\section{Introducción}

La corrupción, como forma de agresión, puede afectar bienes jurídicos muy diversos (Kindhäuser, 2007, p. 2). Esto es, presenta una evidente naturaleza pluriofensiva, tal como lo reflejan los diversos instrumentos internacionales cuyo propósito es que en el ámbito global se adopten medidas de distinta índole para enfrentar este fenómeno ${ }^{1}$. Como ya se ha advertido, existe mayor conciencia en la actualidad acerca de que esta clase de conductas no solo puede socavar las bases de la democracia y afectar la confianza en las instituciones públicas por parte de la ciudadanía, sino que también puede poner en juego reglas fundamentales en el ámbito económico, especialmente aquellas dirigidas a proteger la competencia leal, ya sea en el ámbito local o en las transacciones económicas internacionales ${ }^{2}$. Por lo mismo, no extraña la tendencia actual en el ámbito comparado de ir introduciendo en forma sucesiva variadas modificaciones legislativas con el propósito de modernizar sus mecanismos jurídicos para la prevención y lucha contra la corrupción y así reaccionar en forma más eficiente a tal naturaleza pluriofensiva (Kindhäuser, 2007, p. 11).

En este sentido, resulta especialmente relevante el reconocimiento de la potencialidad lesiva que presentaría la corrupción efectuada en el marco de relaciones llevadas a cabo exclusivamente entre particulares, lo que se refleja, incluso, en que instrumentos internacionales, como por ejemplo, la Oficina de las Naciones Unidas contra la droga y el delito (2014), a través de la Convención contra la corrupción de las Naciones Unidas en su artículo 21, recomienden la tipificación de lo que denominan como "soborno en el sector privado", esto es, "la promesa, el ofrecimiento o la concesión, en forma directa o indirecta, a una persona que dirija una entidad del sector privado o cumpla cualquier función en ella, de un beneficio indebido que redunde en su propio provecho o en el de otra persona, con el fin de que, faltando al deber inherente a sus funciones, actúe o se abstenga de actuar"(p. 20). A su vez, se propone, en este instrumento, la tipificación de la solicitud o aceptación de beneficios indebidos, en los mismos términos que en el caso anterior, efectuada por una persona que dirija una entidad del sector privado.

No obstante lo anterior, la doctrina ha advertido que pese a la conciencia que existe acerca de la lesividad de esta conducta, la realidad comparada demostraría que la reacción frente a este fenómeno es muy desigual, principalmente por el hecho de que no todos los ordenamientos jurídicos que criminalizan la corrupción en el ámbito público, esto es, cuando el sobornado es un representante del Estado, han adoptado medidas equivalentes para reaccionar frente a los casos en que resulta sobornado un representante de una institución privada ${ }^{3}$.

\footnotetext{
${ }^{1}$ Al respecto, en detalle, Carnevali Rodríguez y Artaza Varela (2016, pp. 60 y ss.).

${ }_{2}^{2}$ Por tal razón, por ejemplo, se criminaliza en nuestro país, el delito de cohecho a funcionario público extranjero en los artículos 251 bis y ter del código penal. En relación con este problema ver, Oliver (2003, pp. 42-44). En un sentido similar, Politoff, Matus y Ramírez (2004, p. 508); Rodríguez Collao y Ossandón Widow (2008. pp. 355-357). En contra, Fabián Caparros (2010, p. 78).

${ }^{3}$ Clark (2013, p. 2286). Boles (2014, p. 684).
} 
Tal tratamiento desigual ha sido criticado debido a que ambas formas de corrupción serían delitos funcionalmente equivalentes y, además, ambas afectarían tanto intereses públicos como privados y, por lo mismo, ambas conductas debieran ser entendidas como un mismo delito, solo que perpetuado en contextos diferentes.

También se ha puesto en duda que la corrupción en el ámbito público sea más grave que la que se presenta exclusivamente en el sector privado y resultaría erróneo diferenciar entre ambas por el solo hecho que en un caso intervenga un funcionario público y el otro, no (Boles, 2014, pp. 688 y ss.). Pese a tal diferencia estructural, las similitudes que tendrían entre ambas serían mucho más relevantes para abogar por un trato equivalente, que la importancia que tendría tal diferencia para justificar el trato disímil (Boles, 2014, p. 689). En ambas situaciones nos enfrentaríamos $a$ casos de venta de aquello que nuestra sociedad considera que no puede ser puesto legítimamente en venta (Boles, 2014, p.691).

Sin perjuicio de lo anterior, presentarían en común, en primer lugar, que en los dos casos se estaría frente a una violación de deberes fiduciarios que se deben ya sea en el sector público como en el sector privado y, en segundo lugar, que los dos implicarían necesariamente la traición a una posición de confianza. Tal punto de partida resulta correcto, ya que como señala Kindhäuser (2007, p. 6), la corrupción como forma de agresión se caracterizaría por consistir en un abuso de un poder decisorio transferido, por tanto, en el ámbito de la corrupción en el sector público efectivamente el sobornado termina actuando en contra de los intereses de quien debe representar, es decir, el Estado, y para el caso de la corrupción entre particulares, el sobornado termina actuando en contra de los intereses del principal al cual representa (Boles, 2014, pp. 678-680)4.

Pero, además, al actuar el sobornado en forma incompatible a los intereses de su representado está privilegiando intereses ajenos o personales a los que debe representar. Como tales intereses resultan incompatibles con los del principal, se explica que la corrupción se asimile a una traición a tal posición de confianza. En forma similar Green (201, p. 56) ha sostenido que aceptar un soborno implicaría, en el fondo, el abuso de una posición para la obtención de ventajas personales ${ }^{5}$. El sobornado, al momento de decidir potenciar los intereses de quien representa e intereses ajenos a este último, opta por privilegiar intereses diversos a los que debe cumplir en razón a su posición. Es evidente que tal circunstancia se puede presentar tanto en el ámbito de la representación de intereses estatales como meramente privados.

\footnotetext{
${ }^{4}$ Para el cual el funcionario público está sujeto a deberes fiduciarios para con los ciudadanos con el propósito de desarrollar su función en pos del bienestar de todos. Con todo, esta postura presenta en común con la acá seguida el hecho de reconocer que a través de la corrupción se desvirtúa o se pone en tela de juicio determinadas pautas de comportamiento que derivan de la representación de intereses que lleva a cabo el sobornado. Al respecto (Artaza Varela, 2016, pp. 307-339, 322 y ss.), que al menos en Chile, este problema se ha vinculado con el del sujeto activo en el delito de cohecho y con la exigencia de actuación en nombre del Estado, como se desprende de nuestra jurisprudencia y la interpretación del art. 260 del código penal.

${ }^{5}$ Sostiene que en ambas formas de corrupción se terminaría logrando que quien debe tomar decisiones no quiera o no pueda determinar qué debe hacer en beneficio de su principal.
} 
En este sentido, y tomando en cuenta que tal discusión es de plena actualidad, resulta útil abordar algunos problemas relativos a la necesidad de criminalizar lo que se conoce como corrupción entre particulares y cómo parece conveniente hacerlo, con el objeto de propender a que una eventual modificación del Código penal chileno de cuenta de la complejidad del fenómeno analizado ${ }^{6}$.

Como se podrá apreciar, la corrupción entre particulares puede afectar intereses diversos dependiendo de si se presenta en el desarrollo de actividades de significación pública o no, es decir, cuando se efectúe en el marco de una actividad económica de interés exclusivamente privado. En el primero de los casos, los intereses en juego serían del todo equivalentes a los protegidos por el delito de cohecho, mientras que, en los segundos, el asunto se complejizaría bastante, ya que no resulta tan sencillo determinar cuáles son los intereses que debieran ser considerados dignos de protección por parte del Derecho penal. Como se podrá observar, se suelen confundir intereses dignos de protección con la forma como estos intereses son afectados, es decir, el bien jurídico con la modalidad de ataque específica que se criminaliza. Este problema no solo se refleja en la discusión relativa a los intereses que se ven afectados, sino también en la interpretación de los respectivos penales y los bienes jurídicos efectivamente protegidos por éstos.

El propósito del siguiente apartado es analizar brevemente el problema de la determinación de los intereses que podrían ser entendidos como dignos de protec-

\footnotetext{
${ }^{6}$ Es importante considera que nuestro país no ha sido ajeno a esta tendencia ya descrita y, por lo mismo, ya existen iniciativas que promueven la criminalización de esta conducta. El texto que en definitiva aprueba la Cámara de Diputados (2018), en el marco de la discusión del "Proyecto de Ley que tipifica el delito de corrupción entre particulares y modifica disposiciones del Código penal relativas a delitos funcionarios" es el siguiente:

"§7 bis. De la Corrupción entre particulares.

Artículo 287 bis.- El empleado o mandatario que solicitare o aceptare recibir un beneficio económico, para sí o un tercero, para favorecer, o por haber favorecido en el ejercicio de sus labores la contratación con un oferente sobre otro, será sancionado con la pena de reclusión menor en su grado medio a máximo y multa del tanto al cuádruple del beneficio solicitado o aceptado.

Artículo 287 ter.- Con las mismas penas señaladas en el artículo anterior será sancionado el que, ofreciere o aceptare dar a un empleado o mandatario un beneficio económico, para sí o un tercero, para que favorezca, o por haber favorecido la contratación con un oferente por sobre otro.".

Tal iniciativa no solo contemplaría esta figura para hacer frente a los casos de corrupción cuando el sobornado es un particular y no un representante del Estado, sino que también se ha propuesto incorporar, a través de un nuevo tipo penal (250 ter), un delito similar pero efectuado en el contexto de actividades que presentan una fuerte dimensión pública:

"Artículo 250 ter. El particular que en su desempeño en una persona jurídica cuyo objeto sea la provisión de bienes o servicios públicos tales como educación, salud, infraestructura, servicios básicos u otros de utilidad pública, solicitare o aceptare recibir de un particular un beneficio económico para sí o un tercero para ejercer o por haber ejercido sus funciones de modo parcial o arbitrario, será sancionado con la pena de reclusión menor en su grado medio a máximo, y además, con la pena de inhabilitación absoluta para cargos u oficios públicos temporal en cualquiera de sus grados y multa del tanto al cuádruple del provecho solicitado o aceptado.

El que ofreciere o consintiere en dar un beneficio económico al particular que se desempeña en la persona jurídica referida en el inciso precedente, en provecho de éste o de un tercero, para que ejerza o por haber ejercido sus funciones de modo parcial o arbitrario, será castigado según lo dispuesto en el artículo 250.

A los condenados por los delitos previstos en este artículo se les aplicará además la prohibición establecida en el artículo 35 de la ley № 18.046 sobre Sociedades Anónimas".
} 
ción a través de la tipificación de tales conductas, con el propósito de poder delimitar posteriormente las posibilidades de protección de tales intereses a través de este delito ${ }^{7}$. Como se verá más adelante, pese a los propósitos originales del legislador, la tipificación de tales delitos puede traer aparejada una serie de problemas interpretativos que dificulten justamente la consecución de los objetivos que se pretenden alcanzar o, al menos, se pueden constatar algunos problemas relativos a las posibilidades de protección de tales intereses.

\section{Los intereses que pueden verse afectados por la corrupción entre particulares}

\subsection{Equivalencia lesiva entre la corrupción pública y la privada en casos de difuminación de funciones}

En primer lugar, conviene tener en cuenta que cuando se habla de la potencialidad lesiva de la corrupción entre particulares se puede estar poniendo el énfasis en aspectos muy diversos. Así, por ejemplo, una de las razones que podrían justificar la criminalización de la corrupción entre particulares estaría dada por la necesidad de expandir la protección de los intereses que comúnmente se entienden protegidos o amparados a través de la prohibición de la corrupción en el sector público, ya que en la actualidad sería aparentemente difícil o imposible delimitar adecuadamente qué es aquello que corresponde a la esfera pública y, por el contrario, aquello que es estrictamente privado, por lo que ciertos intereses que pueden verse afectados por la corrupción en el marco del trato con funcionarios públicos también podrían verse afectados cuando se lleva a cabo entre particulares. Como señala Encinar del Pozo, en la actualidad "las funciones públicas y privadas se han desdibujado" (Encinar del

\footnotetext{
${ }^{7}$ Si bien es cierto se debe distinguir entre la ratio legis y el bien jurídico efectivamente protegido por los tipos penales en particular, lo que se pretende acá es identificar exclusivamente intereses que puedan ser objeto de protección a través de la criminalización de tales conductas a través de la observación de las razones que avalan la criminalización de esta conducta en cierta experiencia comparada, con el propósito de efectuar distinciones que puedan ser de relevancia para la toma de decisiones en el ámbito político criminal. A su vez se pretende detectar dificultades, asociadas a la forma como han sido tipificadas estas conductas, que puedan dificultar la consecución de la protección de tales intereses. En este sentido, me interesa acá el problema de la detección de criterios para propender a la "racionalidad instrumental" de las decisiones del legislador, entendiendo por ésta el proceso de valoración de la actividad del legislador que centra su atención en la idoneidad de la misma para el logro de los objetivos que pretende alcanzar. Al respecto, fundamental, Paredes Castañón (2013, p. 340). Ver también, Diez Ripollés (2003, p. 96), desde lo que define como "irracionalidad pragmática". Para esto se hará uso, en primer lugar, del método descriptivo, específicamente de dos opciones para la criminalización de la corrupción entre particulares, la del Reino Unido y la de España debido a lo sintomáticos que resultan para identificar ciertos problemas que podrían derivar de la introducción de este delito en nuestro ordenamiento jurídico. Con lo anterior se quiere clarificar, a su vez, que no se pretende efectuar un análisis exhaustivo de esta clase de delitos en el ámbito comparado, labor que excede las posibilidades de un artículo, y me concentraré en la detección de dificultades relativas a su criminalización a través de la observación, exclusivamente para fines analíticos, de la realidad de los ordenamientos jurídicos ya enunciados.
} 
Pozo, 2016, p. 100), por lo que no podría negarse que una serie de decisiones y actuaciones provenientes del sector privado pueden tener un fuerte impacto en la ciudadanía y ya no podría sostenerse que la corrupción en el marco de las relaciones entre particulares es un asunto meramente privado, sino que, por el contrario, se reconoce que las decisiones corruptas de los empleados de una compañía privada no necesariamente son menos dañinas para la colectividad que "las decisiones corruptas de los funcionarios públicos" (Encinar del Pozo, 2016, p. 101).

Un buen ejemplo de tal punto de partida para decidir criminalizar tales actos, es decir, del reconocimiento de que la corrupción entre particulares puede afectar intereses equivalentes a los de la corrupción pública, se encuentra en ciertas razones por las cuales en el Reino Unido se decide, a través de la Bribery Act de 2010, sancionar los actos de soborno a través de una formula general que abarcara esta clase de conductas.

Uno de los principales problemas que se detectaron en este medio, para mantener la distinción entre corrupción pública y privada, radicaría en la dificultad de definir con suficiente claridad la diferencia entre las funciones propias del sector público y las que deben entenderse como meramente privadas. Incluso, The Law Comission (2008, p. 19). advierte que resultaba obvio extender este delito a los casos en que la ventaja era solicitada o recibida por un funcionario público y, más ampliamente, por todo aquel que desarrollara una función de naturaleza pública. Sin embargo, consideran que la determinación de qué es un "órgano público" era bastante más difícil que en el pasado. Reconocen que gran parte de las funciones o prestaciones que usualmente eran entendidas como una función pública en la actualidad se estaban desarrollando, debido a procesos de subcontratación, por empresas privadas.

La misma dificultad se daría al tratar de definir cuándo un sujeto ostenta la calidad de miembro, funcionario o empleado de un servicio público o si se trata de un privado contratado para cumplir con la función asignada al órgano público. Con todo, consideran que no resultaba aconsejable buscar una definición omnicomprensiva de "organismo público" o de "función pública" para efectos de reformular la prohibición del soborno en el Reino Unido. Es por tal razón que se llega a sostener que resultaría más adecuado para resolver este problema, atender a que estos conceptos variaban de acuerdo a los cambios de la forma o las vías como los servicios eran suministrados a la ciudadanía, tanto en un nivel local como nacional. Por lo mismo, debían ser los tribunales los que decidieran, caso a caso, cuándo la ventaja ofrecida o solicitada estaba vinculada al desarrollo de una función de naturaleza pública (The Law Comission, 2008, p. 19).

Green (2013, p. 61), desde una perspectiva crítica, señala que tal punto de partida no debiera ser sobreestimado, ya que, en un número importante de casos, 
todavía estaríamos en condiciones de establecer cuándo el receptor de un soborno es un actor público y cuándo se trataría de un actor privado, dependiendo de si el sobornado actúa en el marco de una capacidad puramente privada o cuando lo hace en ejercicio de una función pública. Por tal motivo, sostiene que no parece justificado equiparar el tratamiento de ambas, sobre todo si se tiene en cuenta que el argumento de la difuminación, como se verá más adelante, no podría ser aplicado para todos los casos de corrupción entre particulares. Eso sí, reconoce que en ciertos supuestos sería imposible tan diferenciación, lo que se produciría en aquellos casos en que los privados lleven a cabo una función pública significativa o, más bien, desarrollen una actividad de evidente contenido o interés público, proponiendo que en tales ocasiones efectivamente se equipare la reacción punitiva y que se le considere como verdadera corrupción pública.

Este punto es relevante porque podría conducir a ciertos malos entendidos. El núcleo del argumento viene dado por el reconocimiento de que los privados en la actualidad ejercen una serie de actividades que presentan una dimensión pública significativa, lo que no quiere decir, necesariamente, que las conductas de soborno que se lleven a cabo en este contexto puedan ser subsumidas en los tipos penales respectivos de cohecho a funcionario público que existen en nuestro país ${ }^{8}$.

Ahora, basta con plantear un ejemplo sencillo para demostrar que ciertos actos de corrupción ejecutados entre particulares, que no podrían ser subsumidos en las hipótesis vigentes de cohecho, podrían afectar ciertos intereses protegidos por tales delitos. Así, si una persona obtiene a través del ofrecimiento de una ventaja indebida, que un funcionario de un hospital público le otorgue un trato privilegiado adelantando en forma no autorizada su operación quirúrgica, postergando así la de los pacientes que tenían preferencia, afectaría legítimas expectativas de trato imparcial y podrían ser, tanto sobornador como sobornado, sancionados por las respectivas figuras del delito de cohecho. No ocurriría lo mismo si la misma conducta la efectuara un médico de un centro privado, ya que, si bien es cierto es innegable que lleva a cabo una actividad de dimensión pública significativa, no podría ser entendido, en ningún caso como un funcionario público para los efectos de la configuración del tipo penal de cohecho, debido a que no actúa en representación o nombre del Estado.

Si se considera que lo que se pretende asegurar por el tipo de cohecho es determinada forma como los representantes del Estado debieran relacionarse con terceros, esto es, en forma imparcial y que, por lo tanto, se prohíbe la generación de

\footnotetext{
${ }^{8}$ Así, por ejemplo, para que se configure el delito de cohecho se requiere que el sujeto activo (sobornado) desempeñe una función pública lo que tiene que ver más bien, en Chile, con el hecho de que un sujeto actúe en definitiva en representación del Estado o en nombre del Estado, pese a no tener nombramiento formal como funcionario público. Ver, al respecto, Artaza Varela (2016, p. 322 y ss.).
} 
ventajas de unos por sobre otros por razones ilegítimas, es decir, el pago no autorizado de ventajas económicas, se está reconociendo, en forma correlativa, que los ciudadanos y ciudadanas tienen ciertas expectativas legítimas de trato imparcial en su relación con el Estado ${ }^{9}$. Si el Estado decide que ciertas prestaciones que antes estaban a su cargo, pasarán a manos de privados, por ejemplo, debido a procesos de privatización, parece razonable sostener que, al mismo tiempo, los ciudadanos no se vean perjudicados, es decir, no se les cargue con la pérdida de tales expectativas ${ }^{10}$.

En suma, tal punto de partida resulta sumamente relevante para poder introducir una serie de distinciones relativas a las razones que avalarían sancionar los casos de corrupción cuando intervienen exclusivamente particulares, con el objeto de identificar aquellos casos en que efectivamente tales actos puedan entenderse equivalentes a aquellos en que interviene un representante del Estado, frente a los casos en que esto no sucede, ya que la corrupción entre particulares, como se verá a continuación, puede presentar una lesividad específica que no puede ser equiparada a la de la corrupción en el ámbito público.

\subsection{La potencialidad lesiva propia o específica de la corrupción entre par- ticulares}

En segundo lugar, se ha reconocido que fuera de los casos anteriormente descritos, esta conducta presentaría una lesividad propia o específica. Esta dañosidad estaría directamente relacionada con el contexto en el que usualmente se llevaría a cabo, esto es, el de los negocios. Como señala Boles (2014, p. 682), la corrupción privada por lo general se presenta en el marco de la actividad comercial, debido a que ciertas empresas efectúan pagos encubiertos a empleados de otras empresas sin el conocimiento del empleador o el principal, con el propósito de que el sobornado otorgue un negocio al sobornador y de esta forma excluya a los competidores del sobornador. Al respecto, se ha señalado por la doctrina que tal conducta podría afectar intereses muy diversos, por lo que a través de su prohibición se pretendería alcanzar una pluralidad de propósitos, dentro de los que destacan la protección de ciertos deberes de lealtad en el marco de las relaciones laborales o de representación

\footnotetext{
${ }^{9}$ Por tanto, adhiero a la opinión de que lo que se protege por el delito de cohecho no es, sin más, el correcto desempeño de la función pública, sin atender a las razones por las cuales tal función se vincula con el libre desarrollo de la personalidad de los ciudadanos. Al respecto, Artaza Varela (2016, p. 320322).

${ }^{10}$ Tomando en cuenta la relevancia que han adquirido los privados en la prestación de tales servicios es evidente que la exclusión de unos y la preferencia de otros por razones indebidas afecta ciertas expectativas de trato igualitario que también debieran ser protegidos en ciertos contextos. En esta línea se encuentra, sin lugar a dudas, el proyecto de Ley ya descrito supra, n. 12, en su artículo 250 ter, en la medida que podría entenderse prohibido el favorecimiento indebido si se entiende éste como una forma de "haber ejercido sus funciones de modo parcial o arbitrario".
} 
de intereses ajenos (Boles, 2014, p. 682) ${ }^{11}$, la protección de los intereses patrimoniales del titular por cuyo nombre actúa el sobornado ${ }^{12}$ (Encinar del Pozo,2016, p. 96), la protección de ciertas condiciones mínimas de competencia leal, o incluso la administración correcta de los asuntos corporativos de una empresa (Rose, 2003, p. 3).

Una forma de analizar este problema es a través de la observación de los intereses que en el ámbito comparado se tuvieron en consideración como objeto de protección a la hora de criminalizar tales actos de corrupción. En este sentido, se ha señalado que se podrían identificar diversos modelos de incriminación de esta conducta en atención a los diversos intereses que se protegerían en forma prioritaria. Así, por ejemplo, Heine (2003, pp. 10 y ss.) sostiene que el análisis de las diversas legislaciones que criminalizan esta conducta puede verse facilitado recurriendo a tres modelos básicos, sin perjuicio de que parece ser difícil que un modelo se presente en forma pura sin incluir aspectos de otro. Un primer modelo se caracterizaría por considerar que los intereses que deben protegerse a través de la criminalización de la corrupción privada son los intereses económicos corporativos, los intereses de los accionistas o los intereses patrimoniales en sentido amplio (Kindhäuser, 2007, p. $12)^{13}$. Bajo un segundo modelo se privilegiaría la protección de los deberes de lealtad en el ámbito laboral que deben los empleados a sus empleadores. Por último, algunos ordenamientos jurídicos potenciarían, a través de su criminalización, la protección de la libre y leal competencia, así como el buen funcionamiento de los mercados (Heine, 2003, p. 10).

Tales intereses podrían ser agrupados bajo dos categorías diversas de acuerdo al daño causado. Por una parte los efectos relativos a la violación de deberes fiduciarios (donde se debiera incluir además la afectación del patrimonio del principal), esto es, se vinculan a intereses propios del principal del sobornado y, por otra parte, los efectos anticompetitivos vinculados a la afectación de la lealtad de la competencia, por tanto, se relaciona con intereses más bien difusos, como puede ser el de los competidores o incluso supraindividuales como puede ser el de la protección de

\footnotetext{
${ }^{11}$ El efecto lesivo más reconocido, al menos en el ámbito angloamericano, sería el de la violación, por parte del agente sobornado, de sus deberes fiduciarios de lealtad. Reconoce, a su vez, que tales infracciones traerían aparejadas consecuencias económicas adversas para el principal. Ya que en las transacciones económicas el sobornado, normalmente, añadiría subrepticiamente el costo del soborno en los contratos celebrados por el principal.

${ }_{12}$ Por ejemplo, sostiene que tales prácticas producen "consecuencias perjudiciales para las propias empresas que realizan tales actos, que son de distinto tipo. Podemos citar, así, las consecuencias que la corrupción privada tiene en sus principios y valores, dado que socaba la ética empresarial; fomenta la deslealtad en cuanto al empleador y el propio patrimonio de la sociedad (al suponer un sobrecoste sobre el precio del producto) poniendo en peligro los intereses de inversores y accionistas".

${ }^{13}$ En forma crítica sostiene que si se analiza la lesividad de la conducta desde el punto de vista de los competidores no podría ser el patrimonio lo protegido, en la medida que "la protección penal del patrimonio asegura fundamentalmente el statu quo del patrimonio. Como el campo principal de la corrupción económica es la competencia, el daño a los competidores perjudicados se encuentra normalmente en ganancias no alcanzadas".
} 
ciertas condiciones adecuadas de funcionamiento del sistema de mercado (Boles, 2014, p 682) ${ }^{14}$. Lo anterior respondería a que efectivamente la corrupción privada podría "afectar al mismo sistema de mercado y la confianza que se tiene en él" (Encinar del Pozo, 2016, p. 99), ya que socavaría ciertas bases fundamentales del mismo en las que se sustentarían las relaciones comerciales, como son la competencia leal y la selección en función del mérito, las que "resultan indispensables para que los mercados sean fuente de innovación, eficiencia, productividad y crecimiento" (Encinar del Pozo, 2016, p. 99) ${ }^{15}$. Como señalan De la Cuesta Arzamendi y Blanco Cordero (2002), los "efectos sobre la lealtad competitiva de los comportamientos corruptos en el sector privado proceden, en primer lugar, de su incidencia sobre los intereses que confluyen en la competencia" (p. 282). De acuerdo a lo sostenido por tales autores, la corrupción falsearía la competencia en la medida que se terminaría favoreciendo "de manera injusta a un competidor frente a otro" (De la Cuesta Arzamendi y Blanco Cordero, 2002, p. 282), o se terminaría, también, menoscabando la lealtad concurrencial debido a que el sobornado, al adjudicar el contrato respectivo, se habría guiado por razones diversas a la ponderación entre calidad y precio de los productos o servicios (De la Cuesta Arzamendi y Blanco Cordero, 2002, p. 282).

Este punto resulta fundamental, ya que denota la verdadera preocupación que se esconde detrás de la pretensión de prohibir tales conductas, esto es, los efectos lesivos acumulativos para bienes jurídicos supraindividuales o colectivos (Vega Gutiérrez , 2013, pp. 82-91) ${ }^{16}$. Como señala Clark, tal fenómeno podría causar un daño significativo a la sociedad a través de la distorsión de las reglas propias del libre mercado en la medida que podrían terminar incrementando los costos de transacción para todo el resto de los competidores. A su vez, podría generar el efecto de excluir a aquellos competidores que en definitiva no están dispuestos a incrementar tales costos a través de actos de corrupción o, por el contrario, terminen accediendo a hacerlo y adopten tales prácticas con el objeto de poder obtener un negocio (lo que se conoce como efecto contagio)(De la Cuesta Arzamendi y Blanco Cordero, 2002, p. 282). Por tanto, si se efectúa repetidamente y se acaba naturalizando dentro de determinados mercados, podría terminar eliminando un principio fundamental para la efi-

\footnotetext{
${ }^{14}$ Debido a la extensión del artículo no se puede abordar el problema de la eventual suficiencia de tal bien jurídico para ser considerado como relevantes desde una perspectiva penal. Al respecto, desde una perspectiva crítica ver Bolea Bardón (2013, p. 12).

${ }^{15}$ En efecto, y como señala este autor, "la corrupción genera la percepción de que quien no está dispuesto a ofrecer o pagar sobornos no tendrá posibilidades reales de competir". Lo anterior podría traer aparejados efectos nocivos como por ejemplo el retraimiento de la inversión y la disminución de la percepción de seguridad jurídica de un Estado en particular.

${ }^{16}$ En un exhaustivo análisis, sostiene que se ha clasificado habitualmente a los bienes jurídicos supraindividuales en aquellos que tutelan un interés social general, es decir, pertenecen a la totalidad de las personas que integran la comunidad y aquellos que tutelan un interés sectorial o difuso, que serían los que protegen un interés de un grupo más o menos amplio de la sociedad, sin que sea a la totalidad de las personas.
} 
ciencia del sistema de mercado, como es el de la selección en base al mérito (Clark, 2013, p. 2291) ${ }^{17}$ y el de la competencia leal (Encinar del Pozo, 2016, p. 98) ${ }^{18}$.

En el ámbito comparado se refleja claramente la intención de evitar los efectos distorsionadores del mercado aparejados a la corrupción entre particulares. Así, por ejemplo, en el caso Alemán, donde previo a la modificación introducida por la Ley de Lucha contra la Corrupción en 1997, tales conductas ya se consideraban en la Ley contra la Competencia Desleal, y se opta por su criminalización con el propósito de "reforzar la conciencia pública en el sentido de que la corrupción en el sector empresarial era una forma de delincuencia que no sólo debía ser un preocupación de la economía, sino que debía contar con una expresión general de desaprobación ético social de tal comportamiento" (Encinar del Pozo, 2016, p. 175) ${ }^{19}$. Por lo mismo, Tiedemann (2010) señala que para la doctrina dominante en ese país lo que se protege por este delito es en primer lugar "la competencia leal como bien jurídico supraindividual y principio del orden económico" y que, al mismo tiempo, se protegerían también "a los competidores, específicamente en su igualdad de oportunidades y en sus intereses patrimoniales" (p. 309).

Con ciertas diferencias, vinculadas principalmente a la forma como se ha incriminado esta conducta, debe ser considerado el caso del Reino Unido, donde, como señala Green (2013, p. 46), uno de los cambios más radicales relativos a la lucha contra la corrupción, a propósito de la entrada en vigencia de la Bribery Act (2010), sería la forma como se enfrenta la corrupción en el ámbito de los negocios, ya que uno de los principales objetivos de la ley sería acabar con la práctica generalizada del pago de sobornos en el marco de la competencia por la obtención de contratos y, especialmente, la práctica de competir sobre la base de que quien se adjudicaría el contrato en definitiva sería quien pueda pagar el soborno más alto. Como señala Mukwiri (2015), si tal práctica se llegara a generalizar, el "circulo de la corrupción se perpetuaría" (p. 18), lo que podría traer aparejado graves efectos al mercado.

Se pueden considerar también las razones que se adujeron por el legislador español en el año 2010, para la introducción de este tipo penal. En primer lugar, se debe tener en cuenta la influencia que ejerció la Acción Común del Consejo

\footnotetext{
${ }^{17}$ Ver también De la Cuesta Arzamendi y Blanco Cordero (2002, p. 282).

18 Sostiene que la corrupción entre particulares generaría condiciones anticompetitivas ya que "distorsionan la competencia leal y las reglas de una economía de Mercado libre, porque afectan a las condiciones de igualdad entre los actores comerciales". Lo relevante es que tales efectos anticompetitivos también traerían como consecuencia efectos lesivos para los propios consumidores en la medida que podría repercutir negativamente "en la calidad de los productos y servicios" para este último. Como señala este autor, la corrupción podría incentivar a que quien actúa en el mercado se vea inclinado "a favorecer a un proveedor o prestador de servicios inferior o a no cumplir la diligencia debida en la prestación de servicios". Ver también, en relación con los efectos en los consumidores. Ver también, De la Cuesta Arzamendi y Blanco Cordero (2002, p. 283) y Boles (2014, p. 684).

${ }^{19}$ También véase Bolea Bardón (2013, p. 7).
} 
1998/742 JAl que obligaba, definitivamente a España a criminalizar esta conducta (Gil Pascual, 2007, p. 4). ${ }^{20}$ y principalmente la Decisión Marco 2003/568/JAl de 22 de julio, la que termina siendo la principal razón que explica las propuestas de modificación al Código penal respectivo ${ }^{21}$. El objeto de este instrumento sería prevenir las conductas de soborno en el marco de los negocios, debido a su efecto distorsionador de la competencia (García Albero, 2015, p. 554). Esto es, se reconocía que de acuerdo con las directrices internacionales lo que se protegería sería la competencia leal en la adquisición y venta de bienes y servicios ${ }^{22}$. En la modificación al tipo penal operada por LO 1/2015 incluso el legislador español es explícito al señalar que lo que se pretende evitar es la obtención de posiciones de ventaja en las relaciones económicas a través del pago de sobornos (García Albero, 2015, p. 554).

\section{Breve aproximación a las fórmulas de criminalización de la co- rrupción entre particulares}

Una vez se ha constatado ciertas distinciones fundamentales relativas a la definición de los intereses que pueden verse afectados por la corrupción entre particulares, se describirá brevemente cierta experiencia del ámbito comparado, ya que las fórmulas a través de las cuales se pretende hacer frente a tal forma de corrupción son variadas $^{23}$. En este sentido, resulta especialmente relevante atender al menos a dos alternativas distintas que vale la pena considerar. Así, por ejemplo, la opción del Reino Unido, que pretende combatir este fenómeno a través de la criminalización de la corrupción en forma genérica, sin diferenciar si ésta se lleva a cabo en el ámbito público o privado, otorgando criterios relativos a los casos que debieran ser considerados de relevancia penal. Por otra parte, se puede observar la opción española, la que sanciona la corrupción entre particulares con un tipo penal específico, distinto al del delito de cohecho a funcionario público, y cuya aplicación se restringe a los casos de corrupción en el ámbito de los negocios.

\footnotetext{
${ }^{20}$ De acuerdo con el cual este instrumento compelía a los Estados miembros a adoptar las medidas necesarias "para que las conductas de corrupción (activa y pasiva) en el sector privado, incluyendo la complicidad e instigación a las mismas, fueses tipificadas como infracciones penales (arts. 2.2 y 3.2 Acción Común)...".

${ }^{21}$ Ver Blanco Cordero (2015, pp. 540-541). También, Gil Pascual (2007, pp. 5-6).

${ }^{22}$ Ver, al respecto, Blanco Cordero (2015, p. 541), García Albero (2015, p. 555).

${ }^{23}$ Acá solo se considerarán dos alternativas, ya que excede con mucho al propósito de este trabajo un análisis exhaustivo de Derecho comparado. Para tales efectos se puede recurrir al trabajo de Encinar del Pozo (2016, pp. 167 y ss.). Las razones por las que se ha elegido la fórmula propia del Reino Unido es que permite constatar cierto espacio en que la corrupción en el ámbito público y el privado parecen equivalentes, sobre todo por el hecho de que en ciertos casos no podrían ciertamente distinguirse tales ámbitos. Por su parte se describirá también el modelo adoptado por España, con el propósito de indagar en algunos de los problemas que se han planteado en este medio para poder sostener que los tipos de corrupción entre particulares protegen la competencia leal y con qué alcance.
} 


\subsection{La completa equiparación en el Reino Unido entre la corrupción pú- blica y privada a través de un tipo genérico}

En primer lugar, se considerarán las modificaciones introducidas en el Reino Unido por la Bribery Act (2010), instrumento que surge a propósito o en respuesta a las críticas a la legislación anticorrupción existentes a la época, debido a que resultarían inadecuadas para la persecución de formas más intrincadas de corrupción y que la misma resultaba difícil de aplicar en la práctica (Clark, 2013, p. 2302). En la primera sección se sanciona por soborno a quien directamente o a través de un tercero, ofrece, promete u otorga una ventaja económica o de otra clase a otra persona, en forma tal que, debido a tal recompensa, esta persona efectúe una actividad o función relevante en forma indebida (Dunst, Diamant, y Kung, 2011, p. 278)24. La ley colocaría a quien debe llevar a cabo la prestación respectiva en una posición de confianza para desarrollar la misma de buena fe y en forma imparcial y, por lo tanto, considera como soborno el recompensar o inducir el abuso de confianza, así como la falta de buena fe o imparcialidad (Mukwiri, 2015, p. 18).

Como se expone en el informe respectivo de The Law Commission, el elemento básico de este delito estaría constituido por la promesa, ofrecimiento o entrega de la ventaja a otro. A su vez, el injusto moral de esta conducta estaría constituido por el propósito de inducir a otro (no necesariamente quien recibe el soborno) a actuar indebidamente o intentar recompensar tal comportamiento. Como contraparte, el elemento básico del delito llevado a cabo por el receptor de la ventaja consiste en solicitar, estar de acuerdo en recibir o aceptar una ventaja para sí o para otro. El injusto moral consistiría en que la ventaja recibida constituya una recompensa por una actuación indebida, o que esté vinculada al compromiso de efectuar tal infracción de sus funciones, ya sea en forma anticipada o como consecuencia de tal acuerdo entre el receptor y quien otorga o se compromete a otorgar tal ventaja.

Como se puede observar, son varios los aspectos que resultarín sumamente difusos. Por lo mismo, han resultado especialmente importantes los esfuerzos realizados para la delimitación de sus elementos. Así, por ejemplo, la determinación de la actividad o función que resulta penalmente relevante de cara a la atribución de responsabilidad penal por esta conducta y la determinación del comportamiento indebido por parte de quien recibe la ventaja. En este sentido, The Law Commission $(2008$, p. 17) sostuvo que uno de los principales problemas que podría traer aparejada la criminalización de los actos de corrupción en forma indebidamente amplia, sería la de terminar reforzando el comportamiento correcto en contextos inadecuados, esto es, en aquellos que no debieran ser considerados como relevantes para el

\footnotetext{
${ }^{24}$ Señalan que tal enunciado puede ser relacionado con el elemento "corruptly" propio de las FCPA. Ver The Law Commission (2008, p. xii). Ver también Mukwiri, $(2015$, p. 18) y Clark (2013, p. 2303).

Rev. derecho (Coquimbo, En línea) 2019, 26: e3684
} 
Derecho penal, ya que se podría terminar sancionando el mero comportamiento inmoral ${ }^{25}$.

Por lo mismo, y en relación con este primer problema, la Sección 3 de las Bribery Act (2010) describe varias actividades o funciones a propósito de las cuales se puede dar un acto de corrupción, para lo cual utilizaría un lenguaje sumamente impreciso $^{26}$. De acuerdo a Green (2013, p. 46), lo anterior se reflejaría en que no solo se referiría a funciones que puedan ser consideradas de naturaleza pública, sino que también ciertas actividades relacionadas a los negocios (donde se incluye tanto el comercio como las actividades profesionales), o las que se efectúen en el marco del trabajo de una persona empleada o en nombre de un grupo de personas (ya sea de naturaleza corporativa o no). Junto a lo anterior se exige que se presenten ciertas expectativas del desarrollo de tal función o actividad, como que se efectúe de buena fe, en forma imparcial o que se lleve a cabo bajo una posición de confianza ${ }^{27}$.

Por lo mismo, se ha señalado que uno de los principales efectos que derivan de esta técnica legislativa sería el de terminar con la distinción entre la corrupción que ocurre en el marco de una función pública y de la que ocurre en el marco estrictamente particular, optando por equipararlas, al menos en aquellos casos que presenten en común ciertos elementos mínimos, como son: el tratarse del desarrollo de ciertas funciones o actividades de especial relevancia que se ejecutan en nombre de otro y, además, cuando se espera que se desarrollen de determinada forma (desarrollo imparcial o de buena fe).

Como señalan Warin, Falconer y Diamant (2010), tal cláusula expresamente extiende la prohibición del soborno igualmente a los casos de funciones públicas y cierta clase de actividades privadas, sin "discriminar entre las dos" (p. 25). De hecho, en el proceso de modificación de la legislación del Reino Unido una de las desventajas de la legislación anterior que se evidencia, al menos por The Law Commission (2007, p. 19), sería que bajo la legislación vigente antes de la Bribery Act (2010) se efectuaba una distinción imperfecta entre ambas formas de corrupción, debido a que se regían por estatutos diferentes, pese a que en ambos la definición de qué debía entenderse por corrupción era la misma. Uno de sus primeros informes (The Law Commission, 2007) da cuenta de cuáles serían los principales argumentos para continuar con la distinción entre ambas formas, así como para superarla y, en definitiva, equipararlas. No obstante haber señalado que se debía tener en cuenta que a quienes se desem-

\footnotetext{
${ }^{25}$ Se despliega el siguiente ejemplo que podría ser problemático: $\mathrm{H}$ y W tienen una hija en común y se han divorciado recientemente. $\mathrm{W}$ ofrece pagar a $\mathrm{H}$ para que no tenga acceso o contacto con su hija. $\mathrm{H}$ acepta la oferta y recibe el pago. Si el padre acepta tal pago estaría infringiendo su posición de confianza respecto de su hija lo que sería inducido justamente por el pago de la ventaja ofrecida por W. Como explica la Comisión, el Derecho penal no debiera intervenir en casos como el anterior.

${ }^{26}$ Señalado que ocuparía un lenguaje sumamente amplio.

${ }^{27}$ Al respecto, (Bean y MacGuidwin, 2013, p.77)
} 
peñan en el ámbito público se les dirigirían deberes de un estándar más alto que en el sector privado y que tal diferencia se debiera reflejar en la penalidad asignada a cada uno de los delitos, se terminó equiparando igualmente ambas formas de corrupción.

Con todo, y como advierte Green (2013, p. 55), pareciera ser que el propósito del legislador fue entregar a la persecución y a los jueces la responsabilidad de determinar los casos en que parecería razonable perseguir y sancionar, respectivamente, los actos de corrupción, sin entregar, eso sí, suficientes criterios para la determinación de cuándo conviene hacerlo (Bean y MacGuidwin, 2013, p. 79). Como se extrae de los argumentos recientemente expuestos que emanan del legislador, al parecer el aspecto que resultaría central (aunque no el único) para la equiparación introducida, diría relación con la evidente naturaleza pública de actividades que están en manos de privados.

En relación con el segundo problema, es decir, el de la definición del desarrollo de la función en forma indebida, la sección 4 de la Bribery Act (2010), consagra que se entenderá de esta forma si se ejerce en forma tal que "incumpla una expectativa relevante" o si se trata de un incumplimiento de la función que pueda ser entendido por sí mismo como una infracción de esta clase de expectativas. Estas expectativas relevantes deben ser conectadas, a su vez, con los casos en que se espera que un sujeto realice una función de buena fe o en forma imparcial o los casos en que la función justamente surja o provenga de una posición de confianza. De acuerdo a lo establecido por la Sección 5, lo relevante es que se actúe en contra a lo que se esperaría del cumplimiento de tales funciones por parte de un sujeto razonable en el Reino Unido $^{28}$. Para lo anterior se tomará en cuenta la propia legislación (local o nacional) y, en su caso, la costumbre o práctica local si es que la regulación aplicable lo permite (para lo cual también se considerarán las decisiones judiciales que cumplan con ciertos requisitos de publicidad o registro).

De acuerdo a Dunst, Diamant, y Kung (2011), para determinar si se presenta el elemento del desarrollo impropio de la función se puede recurrir tanto a un test objetivo como a uno subjetivo. Por una parte, el test subjetivo busca determinar si el propósito de quien soborna es otorgar la ventaja para inducir a una persona a actuar en forma indebida. Con todo, la determinación de si el sobornado actuó o no en forma indebida remitiría al problema de si su comportamiento u omisión, inducido por el soborno, puede ser entendido como un incumplimiento de alguna "expectativa relevante". Este último término tampoco sería sencillo de delimitar, ya que, a grandes

\footnotetext{
${ }^{28}$ Se debe considerar lo señalado por Fletcher (2006, p. 21), de acuerdo con el cual una de las "más claras particularidades" del discurso jurídico angloamericano sería su "infinita confianza que tenemos en el término razonable", a diferencia del discurso jurídico continental en donde tal término no "figuraría de forma destacada".
} 
rasgos, incluiría cualquier actividad relacionada a los negocios, función pública o cualquiera en la que se espera que un empleado actúe de buena fe, imparcialmente u otra que conlleve una posición de confianza. Para determinar si tales expectativas fueron afectadas se recurre al test de lo que una persona razonable en el Reino Unido esperaría en relación con el desarrollo de esa clase de actividad o función en particular.

A modo de conclusión preliminar se puede sostener que si bien es cierto la técnica legislativa utilizada por el legislador del Reino Unido presentaría la ventaja de reflejar en términos muy adecuados los elementos esenciales de aquello que debe entenderse como un acto de corrupción, expresando así que ésta puede aparecer tanto en el ámbito público como en el meramente privado, manifestaría una serie de desventajas que conviene considerar, en la medida que si bien expresa adecuadamente la equivalencia formal de ambas formas de corrupción, no respondería a ciertas diferencias materiales que parecen sumamente relevantes.

Así, si bien es cierto es resorte del legislador determinar la gravedad de la pena asignada a cada una de las figuras delictivas en particular, a través de la completa unificación de la criminalización de la corrupción no se daría cuenta de importantes diferencias que deben ser consideradas a la hora de su tipificación. Especialmente inadecuada parece la consecuencia relativa a la equiparación absoluta de la gravedad de ambas clases de corrupción, ya que tal decisión corre el riesgo de no representar adecuadamente, como lo ha tratado de demostrar ya Green (2013, pp. 53 y ss.), ciertas valoraciones sociales de suma importancia vinculadas a la necesidad de reacción a través del Derecho penal y a la consideración de que la exclusión de ciudadanos de ciertos servicios o prestaciones de dimensión pública en razón de que no pueden pagar un soborno es una conducta que debe ser diferenciada de aquellas que en el ámbito privado puedan entenderse como un acto, especialmente grave, de competencia desleal o de infidelidad para con el principal.

Por otra parte, y como ya se ha señalado, la evidente diferenciación de bienes jurídicos que podrían resultar afectados por los casos de corrupción entre particulares en contextos de desarrollo de funciones de evidente dimensión pública, frente a los casos de corrupción en los negocios, hace recomendable tipificarlos en forma diferenciada. Lo anterior si bien es cierto no resulta imprescindible, podría facilitar la labor de interpretación y aplicación de los tipos penales respectivos en atención a las posibilidades de afectación de los bienes jurídicos o intereses que se pretenden proteger. 


\subsection{La criminalización de la corrupción entre particulares como tipo au- tónomo restringido a ciertas relaciones comerciales. Breve referencia a la experiencia española}

A diferencia de la fórmula del Reino Unido anteriormente descrita, en España se mantiene la diferenciación entre la tipificación de la corrupción pública de la que se efectúa en el ámbito estrictamente particular y restringido al ámbito de ciertas relaciones comerciales. Este tipo penal se introduce mediante la LO 5/2010 en el artículo 286 bis del código penal español y es modificado en el año 2015 junto a importantes reformas relativas a la lucha contra la corrupción en ese país. Una de las más significativas es la introducción de una nueva sección (Capítulo XI del Título XIII del Libro II) dedicada a los delitos de corrupción en los negocios. De acuerdo a García Albero (2015) se incluyen los delitos de pago de sobornos "para obtener ventajas competitivas (se trate de corrupción en el sector privado o de la corrupción de un agente público extranjero)" (p. 553). Como explica este autor, la modificación habría tenido por principal propósito introducir algunas mejoras técnicas a la tipificación de tales preceptos para garantizar la aplicación de los mismos "en todos los casos en los que, mediante el pago de sobornos, en beneficio propio o de tercero, se obtienen posiciones de ventaja en las relaciones económicas" (García Albero, 2015, p. 554).

De acuerdo a Santana Vega (2015), se sanciona, en primer lugar, a través del delito de corrupción pasiva, a todos aquellos integrantes de una empresa mercantil o sociedad que "tengan capacidad de decisión o de obligarla en el tráfico jurídicomercantil"(p.1003) ${ }^{29}$, aun cuando actúen a través de persona interpuesta, en los casos en que reciban, soliciten o acepten un beneficio o ventaja no justificados de cualquier naturaleza, siempre que la misma esté vinculada al favorecimiento indebido de otro en el marco de la adquisición o venta de mercancías, o en la contratación de servicios o en las relaciones comerciales.

Al igual como se pudo apreciar en el ámbito de la tipificación de este delito en el Reino Unido, acá el sujeto activo del tipo penal de corrupción pasiva solo pueden ser ciertos sujetos. En este caso se trata de quienes actúan en nombre de la empresa, es decir, en representación de la misma. Por tal razón se excluye como sujeto activo

\footnotetext{
${ }^{29}$ Blanco Cordero (2015), señala que "basta con que el sujeto activo tenga capacidad para favorecer a otro en la contratación de servicios o en la adquisición y venta de mercancías" (p. 545). Este punto sería de enorme relevancia en la medida que supondría, de acuerdo al autor, una importante ampliación del tipo penal "que puede dar cabida a la conducta de los comisionistas que actúan en el sector privado". Así también, García Albero (2015, p. 572), quien incluso señala que con la modificación del precepto en cuestión ya no solo es sujeto activo quien asume "la función de contratar en nombre o por cuenta de la empresa", sino que ahora "sujeto idóneo sobornable es quien tiene simplemente capacidad para favorecer a otro en la contratación de servicios o en la adquisición y venta de mercancías".
} 
al titular o empresario de ésta ${ }^{30}$. Con todo, se han evidenciado ciertos problemas vinculados a la opción por incluir al "colaborador de una empresa mercantil", ya que, como expresa Blanco Cordero (2015, p. 543), un colaborador puede ser cualquiera y el Código penal no ha aportado ninguna pauta para la delimitación de este concepto ${ }^{31}$.

Por otra parte, y como indica Blanco Cordero (2015, p. 544), el legislador español parece haber querido dejar al margen a las "actividades de entes sin ánimo de lucro", al haber restringido su aplicación a quienes actúan en nombre de una empresa mercantil o de una sociedad, dejando fuera los casos de representación de asociaciones, fundaciones u organizaciones ${ }^{32}$. Además, y como destaca el autor, uno de los problemas que se ha presentado es el tratamiento que se le debe dar a quienes realizan actos de corrupción en el marco de empresas privadas que presten servicios públicos (Blanco Cordero, 2015, p. 544) ${ }^{33}$. El problema se debe a que el Preámbulo de la Ley Orgánica 5/2010, que introduce por primera vez este delito en el ordenamiento jurídico-penal español, sostiene expresamente que tales casos debieran entrar al campo de aplicación de los delitos de cohecho. Con todo, y debido a que el tipo penal no distingue, y que se ha puesto en duda que los sujetos implicados puedan calificarse legítimamente de funcionarios, se ha sostenido que tales casos deben resolverse aplicando justamente el tipo penal de corrupción entre privados y no el de cohecho (Blanco Cordero, 2015, p. 544) ${ }^{34}$.

Se sanciona, también, a través de lo que se conoce como "corrupción activa", a cualquier persona que, por sí, o por persona interpuesta, prometa, ofrezca o conceda a quien figura como sujeto activo de corrupción pasiva, un beneficio o ventaja no justificados, de cualquier naturaleza, ya sea para ellos o terceros, como contraprestación para que le favorezca indebidamente a él o a un tercero frente a otros en las interacciones comerciales previamente descritas a propósito de la corrupción pasiva.

Como ha señalado Blanco Cordero (2015, p. 546), se trata de un delito común, que puede ser cometido tanto directamente como a través de otra persona y la conducta típica consiste en prometer, ofrecer o conceder beneficios o ventajas de cualquier naturaleza no justificados. Para el autor tal referencia, es decir, el de su carácter

\footnotetext{
${ }^{30}$ Sin embargo, como se verá más adelante, un importante sector de la doctrina crítica tal solución e incluso se han propuesto fórmulas para sancionar al empresario o titular como partícipe de tales delitos.

${ }^{31}$ Especialmente crítico, (García Albero, 2015, p. 570), para quien este término debe ser interpretado en forma restrictiva para evitar que se termine sancionando por esta vía "al simple comisionista sin vinculación alguna" con la empresa, ya sea la que soborna como con la sobornada.

${ }^{32}$ Según el autor así se contradiría lo dispuesto en el art. 2.2 de la Decisión marco 2003/568/JAl, "de acuerdo con el cual la corrupción en el sector privado ha de aplicarse a las actividades profesionales de entidades con fines lucrativos y no lucrativos".

${ }^{33}$ De acuerdo con el cual el Preámbulo de la Ley Orgánica 5/2010 sostenía que tales empresas quedaban dentro del campo de aplicación del delito de cohecho.

${ }^{34}$ Haciendo referencia a informe del Consejo General del Poder Judicial español.
} 
no justificado, "persigue comprender todo lo que el beneficiario no se encuentra legalmente habilitado a aceptar o recibir" (Blanco Cordero, 2015, p. 546). Este último aspecto, es decir, el del favorecimiento indebido como contrapartida a la obtención u ofrecimiento de la ventaja resulta fundamental para comprender la extensión del tipo penal y, como se podrá apreciar más adelante, para dilucidar el problema de los intereses que se pretenden proteger a través de la criminalización de tales conductas.

Con todo, es preciso efectuar algunas consideraciones en particular sobre la realidad española, ya que si bien es cierto la vinculación con la protección de la competencia leal en este medio resulta evidente, al menos si se toma en cuenta las intenciones del legislador y las referencias expresas en los instrumentos internacionales respectivos (Gil Pascual, 2007, pp. 7 y ss). ${ }^{35}$, cierta doctrina de este país ha puesto en duda que éste fuera el bien jurídico exclusivamente protegido, sobre la base de diversas razones. De acuerdo a lo sostenido por Puente Aba (2015), "Ia configuración original de esta infracción delictiva no permitía mantener que ése fuera realmente el auténtico bien jurídico, o al menos que con tal configuración resultara convenientemente tutelado" (p. 916). Por lo mismo se ha sostenido que, pese a las intenciones declaradas del legislador, en realidad el tipo penal solo podría proteger intereses patrimoniales del titular de la empresa o, incluso, ciertos deberes de lealtad que recaen en el representante (Puente Aba, 2015, p. 916) ${ }^{36}$.

Se mantuvo también que el modelo español anterior a la reforma operada en 2015 respondía más bien a uno "hibrido o mixto", así, por ejemplo, de acuerdo con el cual "se requería, cumulativamente, un menoscabo de la competencia leal y una infracción de deberes por parte del corrupto" (Blanco Cordero, 2015, p. 542) ${ }^{37}$. En este sentido, conviene considerar lo señalado por Silva Sánchez, Robles Planas y GómezJara Díez (2011), para los cuales los objetivos de la reforma operada en 2010, serían bastante ambiciosos, ya que buscarían poner fin a la práctica "de que la recepción de incentivos por parte de miembros de una empresa condicione la adquisición de bienes y servicios por parte de ésta" (p. 420). Lo anterior implicaría que serían dos clases de intereses a proteger a través de esta prohibición. Así, en primer lugar, los "intereses de la empresa receptora de los bienes y servicios" (Silva Sánchez, Robles Planas y GómezJara, 2011, p. 420) que son escogidos por el representante que, pese a que resultan de menos calidad o de mayor precio, son elegidos en razón de la ventaja indebida entregada al funcionario con poder decisorio. De acuerdo como a lo señalan tales autores, desde este punto de vista la conducta del empleado puede considerarse como "internamente desleal" y perjudicarían a la empresa representada por el funcio-

\footnotetext{
${ }^{35} \mathrm{Al}$ respecto, en forma crítica, ya que si bien es cierto los instrumentos internacionales pacerían estar preocupados de conductas que tuvieran una "cierta entidad, con capacidad, se diría, para afectar al sistema económico", tal condición no se dejaría "traslucir" en el articulado de tales instrumentos.

${ }^{36}$ Incluso antes de la incorporación del delito, desde una perspectiva crítica a esta postura, De la Cuesta Arzamendi y Blanco Cordero (2002, pp. 278-279).

${ }^{37}$ Ver también, Gil Nobajas (2015, p. 573).
} 
nario corrupto. Al mismo tiempo, el legislador tomaría en cuenta los intereses de los competidores de quien otorga o acepta entregar la ventaja indebida, que ofrecen sus servicios bajo la convicción de la decisión relativa a la obtención del negocio se hará bajo parámetros de eficiencia y no en razón de incentivos ocultos para el resto. Desde este punto de vista el acto de corrupción puede ser entendido como un comportamiento "externamente desleal" (Silva Sánchez, Robles Planas y Gómez-Jara, 2011, p. 420).

Pero, además, como sostiene Puente Aba (2015, p. 916), se habrían presentado en la redacción del tipo una serie de obstáculos para que tal precepto cumpliera con la función efectiva de protección de la competencia. Estos serían, en primer lugar, la "exclusión del empresario como posible sujeto activo de las conductas de corrupción", así como, en segundo lugar, por el hecho de que el tipo penal exigiera que se llevara a cabo el comportamiento "infringiendo con las obligaciones de su cargo" (Gil Nobajas, 2015, p. 574).

En primer lugar, se sostuvo que no parecía coherente con la decisión de proteger la competencia a través de este tipo penal, la de excluir del ámbito de los sujetos activos al titular de la empresa, debido a que este último sería el "primer destinatario de las normas referidas a la competencia" (Gil Nobajas, 2015, p. 579). En este sentido, Navarro Frías y Melero Bosch (2011) sostienen que destaca el hecho de que el legislador haya excluido del círculo de sujetos activos de la corrupción privada en su modalidad pasiva a "aquellas personas que ostentan la condición de empresario, esto es, aquella persona natural o jurídica que, por sí o por medio de representantes, ejercita en nombre propio una actividad económica de producción o de distribución de bienes o de servicios en el mercado, adquiriendo la titularidad de las obligaciones y derechos nacidos de esa actividad" (pp. 11-12). De acuerdo a las mismas, esta exclusión haría surgir las primeras dudas acerca del fin perseguido por el tipo delictivo, ya que si lo que se pretende proteger es la competencia justa y honesta, "no se entiende que se castigue la conducta del empleado que acepta un soborno, pero no esa misma conducta cuando la realiza el titular del establecimiento" (Navarro Frías y Melero Bosch, 2011, p. 12), debido a que no podría afirmarse que tal conducta sea menos lesiva para el bien jurídico que se pretende proteger.

Por tal razón, y pese que el legislador español no modificó esta situación con la reforma del año 2015, parte de la doctrina ha asumido que tal exclusión solo podría ser entendida como una omisión u olvido del legislador ${ }^{38}$. Así, por ejemplo, Navarro Frías y Melero Bosch (2011), han sostenido que si bien es cierto, "el empresario goza de un ámbito de libertad empresarial que le permite decidir más allá de lo que po-

\footnotetext{
${ }^{38}$ Por su parte Blanco Cordero $(2015$, p. 543), señala que tal decisión de no incluir a "los empresarios o, mejor, a los socios o titulares de las empresas" es "algo discutible si el objeto del precepto es castigar los comportamientos que menoscaban la competencia leal".
} 
dría hacerlo el empleado... y que no está sujeto a una especie de genérico deber de imparcialidad u objetividad, como ocurre en el caso de los funcionarios públicos... no es menos cierto que los empresarios son (y de hecho son los empresarios principalmente) los sujetos a los que van referidas las leyes protectoras de la competencia..."(p. 12) 39. Incluso se han presentado fórmulas interpretativas con el objeto de permitir la atribución de responsabilidad penal al titular, por la modalidad de corrupción pasiva ${ }^{40}$.

El gran problema de esta postura es que termina suponiendo que una adecuada protección de la competencia implica necesariamente incluir dentro del sujeto activo al titular, convirtiendo así los casos de corrupción entre particulares en casos completamente equivalentes a los de corrupción en el sector público, en la medida que se terminarían protegiendo expectativas de trato imparcial (bajo la forma de un delito de alteración de la competencia leal) que no tendría respaldo normativo ${ }^{41}$, ya que al titular no se le puede exigir que priorice, en su elección relativa a con quienes va a contratar, razones de mérito por sobre las razones que su propio arbitrio le dicte $\mathrm{e}^{42}$. Por ende, esta postura no solo olvida que es el mismo legislador quien ha optado por restringir la protección de la competencia leal a determinadas modalidades de ataque, como es justamente la corrupción, sino que, además, existen altas probabilidades de que resulte errónea, o al menos excesiva, como propuesta de lege feren$d a^{43}$. El problema que se plantea entonces es el de justificar la sanción al encargado, debido a que resulta extraño sostener que el titular del negocio no tiene deberes de trato imparcial respecto a los competidores, pero si lo tenga su representante.

\footnotetext{
${ }^{39}$ Véase la crítica de Feijoo Sánchez, (2016, p. 90), de acuerdo con el cual las autoras "confunden corrupción con inducción a la infracción de deberes privados (que sería lo que se acabaría protegiendo)...".

${ }^{40}$ Ver al respecto, por ejemplo, Gil Nobajas (2015, p. 580 y ss.).

${ }^{41}$ Fundamental Kindhäuser (2007): "Mientras la Administración Pública está orientada al bien común y el mantenimiento de su capacidad de funcionamiento depende, por tanto, de modo esencial de que el poder de decisión no resulte influenciado indebidamente mediante ventajas, la maximización de beneficios es el principio económico de la economía privada. En este sentido, la consecución de ventajas es completamente adecuada en este ámbito..." (p. 11).

${ }^{42}$ Llega a una conclusión similar, pero en atención a argumentos diversos, Bolea Bardón (2015, p. 11), ya que se basa principalmente en el hecho de que al administrador no se le compete asegurar o proteger la competencia leal y honesta, o que "el administrador no tiene el deber de asegurar el buen funcionamiento del mercado".

${ }^{43}$ En el ámbito español tal propuesta supondría partir de la base que la regulación que protege la competencia leal es obligatoria para los empresarios (la empresa) y que, por lo mismo, se podría defender un modelo puro de competencia. Ver al respecto, Navarro Frías y Melero Bosch (2011, p. 12). Así las cosas, se podría pensar que en el modelo de competencia puro podría tener cabida en la medida que, aunque el administrador no tiene deberes de protección de la competencia estaría, a través de su comportamiento desleal (debido a que no actuaría en consonancia a las obligaciones de su representado) estaría igualmente afectando la competencia. Con todo, el argumento es engañoso, porque asume que del hecho que el empresario sea el obligado de las normas que protegen la competencia, se desprende que tal deber de protección se extiende a toda ocasión, sin atender al rol que juega el empresario en la transacción de la que se trate (es decir, aunque no lo manifiestan expresamente, incluso cuando no está, en definitiva, actuando como competidor).
} 
Como bien señala Feijoo Sánchez (2016), el sujeto central en la corrupción entre particulares, al menos si se pretende comprender como un acto deslealtad dentro de la competencia, es el corruptor (sujeto activo de la corrupción activa), quien sería "el auténtico protagonista que atenta contra la competencia a través de la corrupción". Sin embargo, lo anterior no impediría sancionar al representante, ya que como señala el mismo autor "es esencial para el delito de corrupción que el corrupto sea desleal con la organización para la que trabaja anteponiendo sus propios intereses de forma ilegítima, ya que ésa es la forma en que se afecta la competencia" (p. 92$)^{44}$.

El segundo problema para sostener que lo que protegían estos tipos penales es la competencia leal, era el de la inclusión de la exigencia de infracción de ciertas obligaciones, debido a que habría traído aparejado una serie de problemas interpretativos. Así, García Albero (2015, p. 558) destaca que la doctrina española cuestionaba aspectos de enorme importancia como, por ejemplo, el destinatario de tales obligaciones. Lo que se critica al precepto es que al parecer no quedaba claro quién tenía que incumplir con tales obligaciones, si el representante beneficiario de la ventaja o también el sujeto que entregaba la ventaja al primero (Gil Nobajas, 2015, p. 575) ${ }^{45}$. Tal discusión no era irrelevante debido a que resultó ser fuente de varios malos entendidos. Así, por ejemplo, los argumentos que se plantean relativos a si el sujeto que ofrece o accede a otorgar la ventaja (corrupción activa) estaría incumpliendo sus obligaciones y comportándose en forma desleal para con su titular, si lo que pretende al ofrecer tal ventaja es justamente obtener un negocio en beneficio de su empresa.

Por otra parte, se discutía la clase de obligaciones que debía incumplir el sujeto activo para la configuración del tipo penal, en la medida que tal requisito del tipo podía ser interpretado en diversas formas con consecuencias muy diversas. Así, podía entenderse que bastaba la infracción de obligaciones de lealtad y "rectitud para con su principal" (García Albero, 2015, p. 558), o que lo relevante era la infracción de ciertas obligaciones legales que regularan la actividad del representante en particular o, por último, la infracción de las reglas propias del Derecho de la competencia que se dirigieran a los respectivos sujetos activos. Así, por ejemplo, para cierto sector de la doctrina, la exigencia de incumplimiento de obligaciones para la adquisición y contratación de bienes y servicios podía ser interpretada en forma compatible con el modelo puro de competencia, ya que tal referencia al incumplimiento de obligaciones solo podía entenderse en relación con las obligaciones emanadas de la legisla-

\footnotetext{
${ }^{44}$ Como señala el autor: "La conducta no permitida consiste en que la decisión o futura decisión en el marco de las competencias relativas a la compraventa de mercancías o la prestación de servicios resulta incompatible con los deberes que se derivan de las funciones asignadas".

${ }^{45}$ Parece entender que se exigía en ambos casos. Tal confusión se debe, a mi entender por el hecho de que el legislador español redacta la hipótesis activa de corrupción entre particulares en forma sumamente ambigua.
} 
ción de defensa de la competencia leal respectiva, asumiendo así, aunque no se señala expresamente, una especie de deber de trato imparcial hacia los competidores en el marco de lo que se conoce, en ese medio, como corrupción pasiva.

Como señala García Albero (2015), esta postura postularía que para "condenar a alguien por corrupción -tanto sea activa como pasiva- será preciso concretar en qué conducta de las definidas como competencia desleal en las leyes sobre competencia (y normativa concordante) ha incurrido el sujeto, sea oferente o aceptantes de la ventaja injustificada" (p. 561). Tal autor propone los siguientes ejemplos: "si la dádiva ha tenido por objeto -y ha conseguido- la ruptura de una relación comercial previa con el competidor, sin preaviso... o ha comportado una venta a pérdida, o se traduce en actos de denigración del resto de las ofertas que compiten..., etc." Según este autor, tal interpretación podría resolver algunos problemas que no podrían ser respondidos satisfactoriamente desde otra perspectiva, como por ejemplo, el de la justificación de la equiparación del tratamiento punitivo entre corrupción activa y pasiva, que no tendría justificación alguna desde la "sola perspectiva de la infracción de deberes de fidelidad" y que las "obligaciones legales de la normativa de defensa de la competencia y competencia desleal afectan indistintamente y por igual al que compra y al que vende, al que ofrece y al que acepta", lo que justificaría que frente a las mismas obligaciones se reaccione con las mismas penas (García Albero, 2015, p. 562).

Con todo, tal posición supondría el mismo defecto ya detectado en relación con la tendencia a considerar un error la exclusión del titular del ámbito de los destinatarios de tal prohibición, esto es, el asumir que de la normativa extra penal emanaría un deber de trato imparcial que no estaría dirigido en estricto rigor al competidor, sino que eventualmente incluso al cliente o consumidor y, por tanto, una prohibición de preferir entre un competidor por sobre otro en razones diversas al mérito económico. Que tales disposiciones se dirijan por igual a quienes participan en el mercado, sea vendiendo o comprando, no implica que se apliquen a quienes no deben ser considerados como "competidores".

Para cierto sector de la doctrina, esta segunda fuente de malos entendidos habría desaparecido con la redacción dada al precepto por la Ley Orgánica 1/2015, que elimina la exigencia típica del incumplimiento de obligaciones, ya que solo exige que el beneficio económico indebido sea recibido, solicitado o aceptado como contraprestación para favorecer indebidamente a otro en determinados negocios, lo que para algunos significaría derechamente que el legislador habría optado por un sistema puro de competencia (Gil Nobajas, 2015, p. 576) ${ }^{46}$.

\footnotetext{
${ }^{46}$ Especialmente, para quien tal supresión parecería indicar "que, frente al confuso modelo introducido en 2010, la reforma actual trata de plasmar legislativamente un modelo puro de la competencia". No obstante, reconoce que la nueva redacción "no disipa plenamente las dudas en cuento al modelo de incriminación, por lo que seguirían existiendo elementos disfuncionales... En primer lugar, el mantenimiento de la 
Tal forma de entender el tipo penal explicaría, como señala García Albero (2015, p. 564), que el soborno deba encontrarse en una relación estrictamente instrumental al favorecimiento indebido posterior. Una de las principales consecuencias sería la de que no serían típicos la entrega de regalos o ventajas que se ofrecen con posterioridad al perfeccionamiento de un negocio si se efectúan como agradecimiento por la selección previa ${ }^{47}$. A su vez, tampoco serían típicos los casos de recepción de ventajas para realizar actos propios del cargo o empleo de quien recibe, o la recepción de ventajas en consideración al "cargo de quien los recibe, sin que se pretenda obtener trato de favor en procedimiento concreto de contratación o agradecer un trato pasado" (García Albero, 2015, pp. 564-565).

Por otra parte, se debe entender "favorecimiento frente a otros" como una referencia a los competidores de quien soborna o accede a entregar la ventaja indebida, por lo que deben ser excluidos los "particulares consumidores finales" (García Albero, 2015 , p. 565), ya sea en la modalidad activa o pasiva del delito, ya que, como señala el autor, estos en definitiva no podrían ser considerados como "competidores". En consecuencia, toda relación entre empresa y un consumidor particular debiera entenderse excluida del alcance del tipo penal. De acuerdo a lo señalado por el mismo autor, también debieran excluirse los casos de que se soliciten ventajas o beneficios en forma general, es decir, a todos los competidores o a todo aquel que quiera relacionarse comercialmente con la empresa, en la medida que no se configuraría el requisito de "trato discriminatorio para con el resto de los competidores" (García Albero, 2015, p. 567). Por último, quedaría excluido del tipo penal toda entrega de un beneficio, aún no autorizado por el principal, que no puedan ser entendidos como "potencialmente perjudiciales para otros competidores, como los que puedan producirse en contextos de ausencia de competencia efectiva, o aquellos en que ha de resultar en cualquier caso elegido o favorecido el oferente, por constituir la mejor oferta" (García Albero, 2015, p. 567) ${ }^{48}$.

En síntesis, y como se desprende de lo anteriormente descrito, resulta difícil que esta modalidad del delito sea entendida exclusivamente como un mecanismo

atenuación facultativa en atención a la trascendencia de las funciones del culpable, así como el hecho de que la nueva regulación sigue dejando fuera, al menos aparentemente, al titular de la empresa". Por su parte, Santana Vega (2015), asume que la redacción actual se explica debido a que esta figura no estaría establecida "en beneficio de la empresa, sino de la competencia leal" (p. 1004). No así, para otros que sostienen que la exclusión del titular de la empresa del círculo de sujetos activos hace muy difícil defender que el sistema adoptado sea el de un modelo puro de competencia. Expresamente, Bolea Bardón (2015, pp. 6-7), quien además considera argumentos relativos a un nivel de análisis diverso, esto es, la idoneidad de la competencia como para servir para legitimar la intervención del Derecho penal.

${ }^{47}$ Es decir, solo se sancionarían los casos de "cohecho propio causal o antecedente".

${ }^{48}$ Acá solo interesa describir brevemente el tipo penal en comento, ya que las consecuencias que debieran extraerse de la prohibición penal de la corrupción entre particulares y la protección de la competencia económica serán abordados más adelante. 
de protección de la competencia leal. Se debe tener en cuenta que el acto de corrupción se configura como una actuación incompatible con los intereses declarados por el representado (titular). Esto quiere decir, que incluso la fórmula empleada actualmente por el tipo penal español de "favorecimiento indebido" puede ser entendida en esta clave si se considera que lo relevante acá sería justamente que el representante actúe en forma inconexa a como el titular ha definido que se relacionará -y decidirácon los terceros que compiten por relacionarse comercialmente con aquel ${ }^{49}$. Es cierto que, en la actualidad, en la mayoría de los casos las razones que deben primar para la elección entre oferentes serán las del mérito económico y no otras. Por lo mismo, si el representante, con el propósito de beneficiarse a él mismo o un tercero, decide sobre la base de otras consideraciones ajenas al mérito actúa en forma corrupta. Este tipo penal protegería, así, la competencia en forma indirecta. La pregunta es si bastaría para la sanción tal relación indirecta o mediata con el interés protegido o si se requiere algún plus adicional de injusto para poder predicar la lesividad del mismo.

Por lo mismo, se ha sostenido que esta modalidad del delito se debe entender como un caso de "delincuencia en la empresa" (en contraposición a los casos de delincuencia de la empresa), es decir, un delito cometido contra los intereses de la mis$\mathrm{ma}^{50}$. Es por tal motivo que se ha señalado que para el caso en que el representante termine escogiendo la mejor oferta para la compañía que representa (desde una perspectiva económica) no estaríamos frente a un acto de corrupción en la medida que no actuaría en contra de los intereses de este último ${ }^{51}$.

Incluso si el tipo penal omite la referencia al "incumplimiento de obligaciones", como lo ha efectuado el legislador español, resulta dudoso que estos casos puedan ser entendidos como de "favorecimiento indebido". Con todo, debe reconocerse que este ámbito es bastante problemático, ya que, al mismo tiempo el tipo penal no exige que se perjudique los intereses patrimoniales de la empresa, y para quienes se trata de mera protección de la competencia leal podría no tener sentido la referencia a la afectación de intereses del representado por el sobornado ${ }^{52}$. Sin embargo, no puede desconocerse que si bien es cierto se protege la competencia, este tipo penal ve limitadas sus posibilidades de protección a lo que se entienda por un acto de co-

\footnotetext{
${ }^{49}$ En forma similar, Bolea Bardón (2015, p. 16).

${ }^{50}$ Al respecto, Bolea Bardón (2015, p. 10), utilizando la ya conocida fórmula acuñada por Bernard Schünemann.

${ }^{51} \mathrm{Al}$ respecto, Bolea Bardón (2013, p. 14). Incluso luego de la modificación operada por LO 1/2015 la situación sería la misma para esta autora. Así, Bolea Bardón (2015), señala para el caso de la obtención de comisiones por parte del representante, que "...el injusto propio del delito de corrupción privada surge de la toma de decisión no razonable a favor de una determinada opción (peor oferta seguida de una comisión). Por tanto, hay delito cuando no se puede explicar en términos de racionalidad económica la decisión a favor del producto que representa una peor opción en el mercado..."(p. 8).

${ }^{52}$ Al punto que, por ejemplo, Blanco Cordero (2015, p. 545), señala que tras la modificación sería completamente irrelevante para la configuración del tipo penal el consentimiento posterior del titular, por lo que igualmente en estos casos habría delito (no así antes de la reforma debido a la inclusión dentro de los elementos del "incumplimiento de las obligaciones").
} 
rrupción, por lo que parece imprescindible constatar la actuación en contra de los intereses del titular o principal.

Por tal motivo, uno de los espacios donde más cuidado debiera tener el legislador a la hora de criminalizar esta conducta estaría dada por la consideración de algunas fuentes de malos entendidos que la redacción del tipo podría producir. Uno de los más relevantes dice relación con la eventual exigencia de que, desde el punto de vista de la sanción del representante sobornado se exija o no perjuicio (o peligro de perjuicio) patrimonial para el principal. Las opciones que se presentan son de dos clases. $O$ se asume que se trata de un delito que busca proteger la competencia leal y se entiende que la justificación de la sanción al representante corrupto se debe a que es imprescindible para que tal protección sea efectiva (Feijoo Sánchez, 2016, p. 90), o se reconoce que esta modalidad se trata de un delito diverso al del tipo penal que sanciona al competidor que soborna (o acepta pagar el soborno) y se vincula con la protección de intereses patrimoniales del titular y se tipifica, así, derechamente una modalidad de administración desleal de patrimonio ajeno. En todo caso se debe reconocer que, aunque se opte por un tipo penal que proteja la competencia, aún en esta modalidad, solo podrá hacerlo a través de conductas que puedan considerarse como actos de corrupción en los negocios y, por tanto, de casos en que se constate el abuso del poder decisorio por parte del representante ${ }^{53}$.

En relación con lo anterior, y si al menos se pretende seguir hablando de un delito de "corrupción" -aunque sea en el contexto de relaciones entre particulares-, no parece correcto sostener que la omisión de la inclusión del titular como sujeto activo del delito deba ser considerada como un error o descuido del legislador. Aún más, como se señaló anteriormente, incluir al titular como sujeto activo podría terminar expandiendo el tipo penal a conductas que en definitiva no se tratarían de actos de corrupción, sino que más bien a casos que afectarían exclusivamente reglas de eficiencia de las interacciones económicas. Si algún sentido tiene decir que se protege la competencia leal, incluso sancionando al representante, es porque se entiende que este último debe actuar en pos de la satisfacción de los intereses económicos del representado y que, para tales efectos, debe decidir de acuerdo al mérito económico de sus oferentes y no sobre la base de su propio provecho a costa del principal.

A su vez, y ahora desde la perspectiva de lo que han denominado como corrupción activa, cobra todo sentido concebir la prohibición como un verdadero caso de competencia desleal, en la medida que el hecho de pretender ser elegido en favor

\footnotetext{
${ }^{53}$ Por eso parece especialmente interesante la discusión que se ha dado en el ámbito español relativa al pago de comisiones al representante por parte del competidor, y que no todos los casos pueden ser entendidos como actos de corrupción. Sin embargo, en atención a su propia forma de entender este delito, Bolea Bardón (2015) señala: "De modo que únicamente cuando la conducta de favorecimiento vulneradora de las reglas de la libre competencia es idónea para perjudicar los intereses de la empresa para la que trabaja el corrompido, cabe apreciar el delito..." (p. 15).
} 
de otros competidores a través de un beneficio indebido debe ser entendido, en todo caso, como una forma de competencia desleal, es decir, toda aquella forma de obtener un cliente, o imponerse por sobre los competidores, sobre la base de razones diversas a las del propio mérito económico ${ }^{54}$.

Con todo, es imposible delimitar qué es lo que escaparía del propio mérito económico si no se atiende a las propias reglas del juego que caracterizan el tipo de interacción de la que se trate. Por eso se comprende además que, en el ámbito comparado, uno de los principales problemas que se hayan presentado en el ámbito de la corrupción en los negocios diga relación con la determinación de si ciertos pagos efectuados en el marco de éstos deben ser entendidos como un acto de corrupción o única y exclusivamente como "contactos sociales permitidos" 55 , así, por ejemplo, un gasto hecho de buena fe como una muestra de hospitalidad o para efectos promocionales ${ }^{56}$.

Al respecto, conviene considerar nuevamente la experiencia del Reino Unido y atender a lo establecido por el Ministerio de Justicia en una serie de directrices para la aplicación de la Bribery Act (2010). Así, se reconoce que para que un caso de "hospitalidad" sea considerado soborno se debiera demostrar que tal gasto fue efectuado con el principal propósito de inducir al beneficiario a vulnerar las expectativas de actuación de buena fe, en forma imparcial, o de acuerdo a su posición de confianza, lo que debe ser juzgado de acuerdo al criterio de la "persona razonable del Reino Unido" ya descrito.

Lo mismo sucedería con los gastos en promoción o marketing, esto es, aquellos que tengan por objeto mejorar la imagen de la organización comercial o que estén dirigidos a presentar sus productos o servicios o a establecer relaciones comerciales cordiales, los que son entendidos y reconocidos como parte importante de los negocios, por lo que, de acuerdo a las directrices señaladas, no debieran ser entendidos como actos prohibidos por la Bribery Act (2010). Con todo, Bean y MacGuidwin $(2013$, p. 16) señalan que, en realidad, tales directrices no aportan ningún criterio útil para diferenciar casos que deban ser entendidos como actos de corrupción de otros que no, ya que no se entregarían criterios rectores para definir qué debe entenderse por legítimo y tampoco cuándo entender que la ventaja ofrecida o entregada tiene

\footnotetext{
${ }^{54} \mathrm{Al}$ respecto, Bolea Bardón (2015, p. 15), para quien cobraría especial relevancia la figura de la "inducción a la infracción contractual por parte de empleados de otra sociedad". Respecto al concepto de deslealtad en la competencia ver, Contreras Blanco (2012, pp. 22-27).

${ }^{55}$ Ver al respecto Feijoo Sánchez (2016), el que excluye, en primer lugar, los casos en que los beneficios o ventajas "carezcan de idoneidad desde una perspectiva intersubjetiva para influir en una decisión comercial" (p. 95).

${ }^{56} \mathrm{Al}$ respecto resulta sumamente útil remitirse también al desarrollo, en el ámbito estadounidense, de las FCPA. Éstas contienen entre las posibilidades de defensa para los acusados el sostener que el pago, en definitiva, fue efectuado de buena fe. Esto implica que los gastos efectuados debieran ser considerados como razonables y efectuados de buena fe con el objeto de promocionar, demostrar o explicar productos o servicios. Ver al respecto, (Carnevali Rodríguez y Artaza Varela, 2016, p. 80 y ss).
} 
por propósito asegurar una ventaja en los negocios ${ }^{57}$. A su vez, de la discusión propia de este medio también parece que existieran dudas acerca de que solo se requiera esta conexión entre lo ofrecido y la intención de obtener una ventaja, ya que tal ventaja debiera entenderse, a su vez, como una ventaja indebida en el marco de las relaciones comerciales, es decir, se debe entender como una forma de influir indebidamente en quien recibe tal beneficio (Bean y MacGuidwin, 2013, p.16).

Se ha reconocido así que no es fácil determinar cuál sería el límite entre la "hospitalidad generosa" y el soborno como conducta delictiva, ya que en definitiva es evidente que los gastos en hospitalidad son generalmente efectuados con el propósito de influir en la toma de decisiones en los negocios, lo que no implica que deban considerarse necesariamente indebidos en la medida que no puedan ser entendidos como idóneos para influir para que la contraparte actúe en forma incorrecta Dunst, Diamant, y Kung (2011, p. 277). Las directrices emanadas del Ministerio de Justicia del Reino Unido solo aportarían el dato de que tal definición dependería siempre del contexto en el que se efectúen, para lo cual debiera considerarse, por ejemplo, la clase y envergadura de la ventaja ofrecida, la forma y la manera en que es suministrada, el nivel de influencia que puede tener el funcionario al que se le otorga, lo fastuoso que pueda resultar el gasto y las normas o el estándar en esta clase de gastos en el sector del que se trate (Dunst, Diamant, y Kung, 2011, p. 277).

Como ya se ha señalado con anterioridad, este problema debiera ser resuelto desde la misma estructura de un acto de competencia desleal (y de corrupción simultánea por parte del representante sobornado). Por lo mismo, no puede ser entendido como competencia desleal (y corrupción) todo aquel gasto cuyo sentido, desde los parámetros propios de la interacción económica de la que se trate, sea permitir que el encargado decida en forma correcta teniendo a la vista toda la información relevante para tales efectos. Así, por ejemplo, los gastos necesarios para un conocimiento acabado del producto o su producción no debieran ser entendidos como un caso de deslealtad en la competencia, en la medida que no se desmarquen de la pretensión de obtener el negocio en base al mérito económico y, al mismo tiempo, la decisión por parte del encargado sobre la base de tales razones, no resultaría incompatible con los intereses de su representado.

En este sentido, lo que podría resultar más problemático, sin lugar a dudas, serían los denominados como gastos de hospitalidad. Se debe tener en cuenta, en primer lugar, que dentro del concepto de mérito económico se debe incluir, también,

\footnotetext{
${ }^{57}$ Por lo mismo, en el ámbito estadounidense se ha reconocido también que esta defensa resulta sumamente difusa, ya que no resulta sencillo determinar cuándo los gastos efectuados para generar relaciones comerciales o beneficios futuros se transformarían en un soborno. Al respecto, Shingler (2013, p. 551). Ver también Pacinil (2012, p. 572), quien a través del análisis de casos da cuenta de ciertos criterios que resultan de utilidad para determinar cuándo un pago debe ser considerado razonable.
} 
la sustentabilidad de las relaciones económicas a futuro y, por tanto, también las relaciones adecuadas entre las partes. Con todo, es evidente que en este ámbito resulta sumamente difícil delimitar qué es un pago de hospitalidad frente al que pueda ser considerado como un soborno. Para tales efectos, no queda otra alternativa que atender a la razonabilidad del pago dentro del contexto en particular y las reglas del juego que se han generado en tal ámbito. Por ende, todo pago de hospitalidad debe entenderse también en relación con el desarrollo de un negocio (futuro u actual) y en la medida que ya no pueda predicarse de éste ninguna vinculación razonable con el mismo, se podría entender ya como un caso de deslealtad en la competencia.

Sin embargo, lo anterior no significa que la conducta sea por este solo hecho punible, ya que acá se puede identificar, nuevamente, un último espacio de fuentes de malos entendidos que pueden surgir de este delito, de acuerdo a como se encuentre redactado. El problema que se presenta ahora es determinar qué sucede en los casos que desde la perspectiva de la conducta del competidor que soborna se pueda entender, sin duda alguna, como un caso de competencia desleal (piénsese en casos de gastos desmedidos en hospitalidad, o pagos de becas educacionales, gastos en entretenimiento, etc.) pero que, al mismo tiempo, no pueda ser considerado, ahora desde la perspectiva de la conducta del sobornado, como un acto contrario a los intereses del principal porque, en definitiva, resulta que igualmente se trata de la mejor oferta para éste último y el gasto respectivo ha corrido por cuenta del competidor y no en desmedro de los intereses patrimoniales de la empresa.

Con esto se quiere decir que un proceso adecuado de discusión de la criminalización de tales conductas obligaría a considerar esta situación y a determinar, previamente, si se pretende introducir dos tipos penales autónomos o si resultan tipos penales relacionados entre sí de tal forma que solo resulta sancionable la conducta del competidor que soborna si al mismo tiempo resultaría punible (en su caso) la aceptación por parte del representante sobornado, por tanto, si se trata de un acto de corrupción desde tal perspectiva.

\section{Conclusiones}

A la hora de analizar la necesidad de criminalizar lo que se conoce como corrupción entre particulares no basta con partir de la base de la mera constatación de que esta conducta también puede afectar intereses de relevancia jurídico penal. Para hacerlo en forma adecuada se debe partir de la distinción fundamental entre dos clases de intereses que podrían verse afectados por tales actos de corrupción. En primer lugar, nos enfrentamos a casos en que éstas resultarían idóneas para afectar los mismos intereses que los protegidos a través de los tipos penales a través de los cuales se enfrenta al soborno en el sector público, debido a que en tales supuestos $y$, 
como se pudo observar, también estarían en juego la vigencia de expectativas de trato imparcial en el desarrollo de actividades o prestación de servicios revestidos de una evidente dimensión pública. Por otra parte, y, en segundo lugar, se constató que esta conducta podía afectar intereses sumamente diversos vinculados, más bien, a la protección de condiciones adecuadas de lealtad en la competencia para el desarrollo de los negocios.

Por lo mismo, y tomando en cuenta la importancia de la claridad del bien jurídico protegido para efectos de interpretación de las normas de comportamiento en sede penal, no parece conveniente la criminalización de la corrupción entre particulares en un único tipo penal sin efectuar la distinción anteriormente planteada. Una de las principales razones es que cuando hablamos de corrupción privada con dimensión pública los límites a la criminalización provenientes de las exigencias de la toma de decisiones incompatibles con los intereses que se representan son muy distintas a los casos en que están en juego intereses de carácter económico. Así, por ejemplo, se comprende la necesidad de verificar que el representante actúe en contra de los intereses patrimoniales de su representado en el segundo supuesto, pero, en modo alguno, en el primero.

Como se pudo apreciar, resulta especialmente problemática la toma de decisiones relativas a la forma y limites asociados a la protección de la competencia leal de los actos de corrupción entre particulares. Como se pudo apreciar, si no se identifica adecuadamente la forma de agresión (corrupción) de los intereses protegidos, es sumamente probable que se puedan potenciar malos entendidos en sede de interpretación de los tipos penales respectivos. Así, por ejemplo, la tendencia a pretender trasformar esta figura en una especie de atentado general contra la competencia leal, dirigiendo deberes de imparcialidad en la toma de decisiones incluso al titular del negocio del representante sobornado que no tendrían, al menos en nuestro país, respaldo extra penal alguno.

De esta forma se constata la complejidad del asunto que se discute en la actualidad y que tiene un impacto directo en la extensión de la prohibición que emana de tales tipos penales. Por una parte, se debe definir, desde la perspectiva de la conducta del sobornador qué tipo de conductas se entienden como casos de competencia desleal, por tanto, de pago de beneficios considerados como indebidos, ya que escapan a lo que se entiende como mérito económico. Para tales efectos se debiera recurrir a valoraciones propias de la institución que la caracteriza, esto es, la competencia desleal, con el propósito, por ejemplo, de abordar adecuadamente supuestos problemáticos como los de gastos de hospitalidad, de promoción de productos o, por último, de supuestos que no sean idóneos para producir efectos relevantes para eventuales competidores. 
Por otra parte, resulta de suma importancia que de la redacción del tipo penal se denote que no cualquier caso de competencia desleal en la forma de un pago indebido (desde el punto de vista de la conducta del sobornador) resulte merecedor de pena, debido a la exigencia de que se trate, al mismo tiempo de un acto de corrupción desde la perspectiva del sobornado. Por lo mismo, se debe determinar qué clase de decisiones adoptadas por el representante del titular, mediadas por la entrega del tal beneficio, deben ser comprendidas como incompatibles con los intereses del titular y el papel que debe jugar ahí la constatación de la afectación de intereses patrimoniales de este último.

\section{Agradecimientos}

El presente artículo se enmarca en el proyecto de investigación FONDECYT $\mathrm{N}^{\circ}$ 1150148 titulado "Corrupción y actividad empresarial. Análisis conceptual para una nueva sistematización", cuyo investigador responsable es el Dr. Raúl Carnevali Rodríguez. Se agradece la colaboración de los Sres. Ayudantes Germán Acevedo Mundaca, Luciano Rojas Morán y Ricardo Mendoza Tapia, por sus valiosos aportes en el desarrollo del artículo.

\section{Referencias Bibliográficas}

Artaza Varela, O. (2016). La utilidad del concepto de corrupción de cara a la delimitación de la conducta típica en el delito de cohecho. Política Criminal, 11(21), 307-339. https://doi.org/10.4067/s0718-33992016000100011

Bean, B. y MacGuidwin, E. (2013). Unscrewing the inscrutable: the UK bribery act 2010. Indiana international \& comparative law review, 23(1), 63-109. Recuperado de https://bit.ly/319j16V

Blanco Cordero, I. (2015). Delitos de corrupción en los negocios: (artículos 286 bis a 286 quater). En M. Gómez Tomillo (Dir.), Comentarios prácticos al código penal (Vol. 3, pp. 539-560). Pamplona: Aranzadi.

Bolea Bardón, C. (2013). El delito de corrupción privada. El bien jurídico, estructura típica e intervinientes. InDret, 13(2), 1- 29. Recuperado de https://bit.ly/33mJrU5

Bolea Bardón, C. (2015). Deberes del administrador y prácticas de kick-back. Revista electrónica de ciencia penal y criminología, (17), 17-17. Recuperado de https://bit.ly/1UDIGk2 
Boles, J. (2014).The two faces of bribery: international corruption pathways meet conflicting legislative regimes. Michigan journal of international law, 35(4), 673-713. Recuperado de https://bit.ly/2M3TyHt

Carnevali Rodríguez, R. y Artaza Varela, O. (2016). La naturaleza pluriofensiva y transnacional del fenómeno de la corrupción. Desafíos para el derecho penal. lus et praxis, 22(2), 53-90. https://doi.org/10.4067/S0718-00122016000200003.

Chile, Cámara de diputados. (2018). Tipifica el delito de corrupción entre particulares y modifica disposiciones del Código Penal relativas a delitos funcionarios, Boletín, (10155-07). Recuperado de https://bit.ly/2B4Pwsc

Chile, Ministerio de Justicia. (1874). Código penal. Recuperado de http://bcn.cl/1 uvs0

Clark, S. (2013). New solutions to the age-old problem of private-sector bribery. Minnesota law review, 97(6), 2285-2319. Recuperado de http://bit.ly/33ITRn0

Contreras Blanco, Ó. (2012). La competencia desleal y el deber de corrección en la ley chilena. Santiago: Eds. Universidad Católica de Chile.

De la Cuesta Arzamendi, J. y Blanco Cordero, I. (2002).La criminalización de la corrupción en el sector privado: ¿Asignatura pendiente en el derecho penal español?. En J. L. Díez Ripolles (Coord.), La ciencia del derecho penal ante el nuevo siglo: Libro homenaje al profesor doctor José Cerezo Mir (pp. 257-290). Madrid: Tecnos.

Diez Ripollés, J. L. (2003). La racionalidad de las leyes penales. Madrid: Trotta.

Dunst, L., Diamant, M., Kung, T. (2011). Hot off the press: resetting the global anticorruption thermostat to the UK breibery act. Business law international, 12(3), 257292. Recuperado de http://bit.ly/2nEuSfs

Encinar del Pozo, M. Á. (2016). El delito de corrupción privada en el ámbito de los negocios. Navarra: Aranzadi.

España, Jefatura del Estado. (1995). Código penal. Madrid: Boletín Oficial del Estado. Recuperado de https://bit.ly/2Tx5gLA

Fabián Caparros, E. (2010). La corrupción de funcionario público extranjero en el derecho penal chileno a la luz del convenio de la OCDE de 1997 (aspectos sustantivos). En J. E. Cheyre, J. M. Olivares Tramón, N. Rodríguez García (Coord.), Chile en el Club de los países desarrollados. Santiago: CEIUC. Recuperado de http://bit.ly/2OBvkpK 
Feijoo Sánchez, B. (2016). Orden socioeconómico y delito. Cuestiones actuales de los delitos económicos. Buenos Aires: B de F.

Fletcher, G. P. (2006) Lo justo y lo razonable. (F. Muñoz Conde y P. Busato, Trads.). Buenos Aires: Hammurabi.

García Albero, R. (2015) Corrupción en los negocios y modificación del cohecho. En G. Quintero Olivares, (Dir.), Comentario a la reforma penal de 2015. Pamplona: Aranzadi.

Gil Nobajas, M. S. (2015). El delito de corrupción en los negocios (art. 286 bis): análisis de la responsabilidad penal del titular de la empresa, el administrador de hecho y la persona jurídica en un modelo puro de competencia. Estudios penales y criminológicos, 35, 567-624. Recuperado de http://bit.ly/2MzI9hT

Gil Pascual, A. (2007). Bases para la delimitación del ámbito típico en el delito de corrupción privada. Contribución al análisis del art. 286 bis del código penal según el proyecto de reforma de 2007, Revista electrónica de ciencia penal y criminología, (09), 09-13. Recuperado de http://bit.ly/2M62IU7

Green, S. (2013). Official and comercial bribery: should they be distinguished?. En J. Horder, P. Alldridge, (Eds.), Modern bribery law, comparative perspectives (pp. 66-94). Cambridge: Cambridge University Press. https://doi.org/10.1017/CBO9781139088398.

Heine, G. (2003). Comparative analysis. En G. Heine, B. Huber y T. Rose (Eds.), Private commercial bribery. A comparison of national and supranational legal structures (Vol. S. 94, pp. 603-656). Freiburg im Breisgau: Edition luscrim. Recuperado de http://bit.ly/318BArE

Kindhäuser, U. (2007).Presupuestos de la corrupción punible en el Estado, la economía y la sociedad. Los delitos de corrupción en el código penal alemán, Política Criminal, 1(3), 1-18. Recuperado de https://bit.ly/21197CH

The Law Commission. (2007). Reforming bribery. A consultation paper (Vol. 185). London: Law Commission. Recuperado de https://bit.ly/312NhQN

The Law Commission. (2008) Reforming Bribery (Vol. 313). London: House of Commons. Recuperado de https://bit.ly/2IHQZJj

Mukwiri, J. (2015). British law on corporate bribery. Journal of financial crime, 22(1), 16-27. https://doi.org/10.1108/JFC-12-2013-0072 
Navarro Frías, I. y Melero Bosch, L. (2011). Corrupción entre particulares y tutela del mercado. Indret, 11(4), 1-40. Recuperado de https://bit.ly/2rBRif7

Oficina de las Naciones Unidas contra la droga y el delito [UNODC]. (2004). Convención de las Naciones Unidas contra la corrupción. Viena: Naciones Unidas. Recuperado de https://bit.ly/2oN8w5S

Oliver, G. (2003). Últimas modificaciones en la regulación del delito de cohecho (ley No 19.829 de 1999). Revista chilena de derecho, 30(1), 39-53. Recuperado de https://bit.ly/2IHXCLp

Pacini, C. (2012). The foreign corrupt practices act: taking a bite out of bribery in international bussines transactions. Fordham journal of corporate \& financial law, 17(2), 545-589. Recuperado de https://bit.ly/2q0obFa

Paredes Castañón, J. M. (2013). La justificación de las leyes penales. Valencia: Tirant lo Blanch.

Politoff, S., Matus, J. P. y Ramírez, M. C. (2004). Lecciones de Derecho penal chileno. Parte Especial (2a ed.). Santiago: Editorial jurídica de Chile.

Puente Aba, L. M. (2015). Corrupción en los negocios (art. 286 bis CP). En J. González Cussac (Dir.), Comentarios a la reforma del Código penal de 2015. Valencia: Tirant lo Blanch.

Rodríguez Collao, L. y Ossandón Widow, M. (2008) Delitos contra la función pública (2a ed.), Santiago: Editorial jurídica de Chile.

Rose, T. (2003). Introduction. En G. Heine, B. Huber y T. Rose (Eds.), Private commercial bribery. A comparison of national and supranational legal structures (Vol. S. 94, pp. 1-8). Freiburg im Breisgau: Edition luscrim. Recuperado de http://bit.ly/318BArE

Santana Vega, D. (2015). Sección 4ª . De la corrupción entre particulares. En M. Corcoy Bidasolo, y S. Mir Puig (Dirs.), Comentarios al código penal. Reforma LO 1/2015 y LO 2/2015. Valencia: Tirant lo Blanch.

Shingler, E.(2013). The foreign corrupt practices act: a new approach to the reasonable and bona fide expenditure defense. The Brooklyn journal corporate financial \& commercial law, 7(2), 537-560. Recuperado de https://bit.ly/31c39k5 
Silva Sánchez, J. M. y Robles Planas, R. y Gómez-Jara, C. (2011). El delito de corrupción entre particulares (art. 286 bis). En J. M. Silva Sánchez (Dir.), El nuevo código penal. Comentarios a la reforma. Madrid: La Ley.

Tiedemann, K. (2010). Manual de derecho penal económico. Parte general y especial. $(\mathrm{H}$. Hernández Basualto, Trad.). Valencia: Tirant Lo Blanch.

United Kingdom, Ministry of Defence Police Force. (2010). Bribery act. London: The Stationery Office Limited. Recuperado de https://bit.ly/1FIc0c7

Vega Gutiérrez, J. (2013). Mercado de valores en derecho penal. Buenos Aires: B de F.

Warin, F., Falconer, C. y Diamant, M. (2010). The British are coming!: changes its law on foreign bribery and joins the international fight against corruption. Texas International Law Journal, 46(1), 1-72. Recuperado de https://bit.ly/2B5Ulw2

\section{Para citar este artículo bajo Norma APA 6a ed.}

Artaza Varela, O. (2019). Corrupción entre particulares: lesividad de la conducta y consecuencias en sede de tipificación de acuerdo al análisis comparado. Revista de Derecho (Coquimbo. En línea), 26, e3684, http://doi.org/10.22199/issn.0718-97532019-0006 